\title{
The use of selected reaction monitoring in quantitative proteomics
}

Selected reaction monitoring (SRM) has a long history of use in the area of quantitative MS. In recent years, the approach has seen increased application to quantitative proteomics, facilitating multiplexed relative and absolute quantification studies in a variety of organisms. This article discusses SRM, after introducing the context of quantitative proteomics (specifically primarily absolute quantification) where it finds most application, and considers topics such as the theory and advantages of SRM, the selection of peptide surrogates for protein quantification, the design of optimal SRM co-ordinates and the handling of SRM data. A number of published studies are also discussed to demonstrate the impact that SRM has had on the field of quantitative proteomics.

The field of MS-based proteomics has undergone shifts in emphasis during its history. During its nascency, the field was concerned with qualitative experiments, whereby samples were analyzed to catalog which proteins were present [1]. Around the turn of the century, focus shifted towards quantitative experiments, which were facilitated by differentially labeling samples with stable isotopes to allow mass resolution of proteolytic peptides of identical sequence using a mass spectrometer, thus allowing their relative quantification. The first reported approach of this nature was isotope-coded affinity tags $[2,3]$, and was followed by further tagging approaches such as tandem mass tags [4], isobaric tag for relative and absolute quantification (iTRAQ) [5] and stable-isotope dimethyl labeling [6,7]. These strategies involve chemical derivatization of the proteins or peptides with a synthetic reagent. An alternative labeling strategy, stable-isotopelabeled amino acids in culture (SILAC) [8,9], incorporates the label directly into the protein as it is being synthesized by the cell, leading to a uniformly labeled population of proteins after approximately five cell doublings [10]. Several label-free strategies for protein quantification have also been reported, using either intensitybased measurements [11] or spectral counting [12], with intensity-based measurements yielding more accurate quantification data [13]; however, both approaches generally lack the precision and accuracy of label-based methodologies. The common aspect of all of these approaches is that they are implemented in relative quantification experiments. The output of this type of study is such that the abundance of a protein in one sample is expressed relative to the amount of the same protein in another sample, for example, a healthy control sample compared with a diseased state; two different growth conditions for cultured cells and so on. Whilst yielding undeniably useful information in certain contexts, the values are unsuitable for interlaboratory comparison, can not be used to build mathematical models to understand cellular processes from a systems biology perspective and do not determine the amounts of biomarkers of disease in clinical samples [14-17]. Consequently, in the last few years, the interest in absolute protein quantification as an adjunct to relative approaches has increased, facilitated by improvements in instrumentation and software. Absolute quantification, as the name suggests, allows determination of the amount of a given protein present in a sample without recourse to comparison with another sample. For example, rather than saying there is twice as much of a given protein in one sample, compared with another, it is possible to define the number of copies of a given protein per cell or for a concentration measurement, for example, $\mathrm{ng} \mathrm{m}^{-1}$, to be determined.

\section{Strategies for absolute quantification of proteins}

A number of approaches have been reported for absolute quantitative proteomics in recent years. Whilst label-free methodologies for absolute quantification have garnered interest due to their ease of implementation and low financial costs [18-21], it is generally accepted that more analytically rigorous data, specifically more accurate and precise quantitative measurements,
Stephen W Holman*1, Paul F G Sims ${ }^{2}$ \& Claire E Eyers'

'The Michael Barber Centre for Mass Spectrometry, School of Chemistry, Manchester Institute of Biotechnology, University of Manchester, I3I Princess Street, Manchester, MI 7DN, UK

${ }^{2}$ Faculty of Life Sciences, Manchester Institute of Biotechnology, University of Manchester, 13I Princess Street,

Manchester, MI 7DN, UK

*Author for correspondence:

Tel.: +44 I6I 306482 I

Fax: +44 161306 8918

E-mail: stephen.holman@

manchester.ac.uk 


\section{Key Term}

Quantotypic peptide:

A peptide that is quantitatively representative of the protein from which it derives. This peptide must be unique within the proteome of interest, resistant to artefactual and post-translational modification, excised to completion upon proteolysis and detectable by LC-MS.

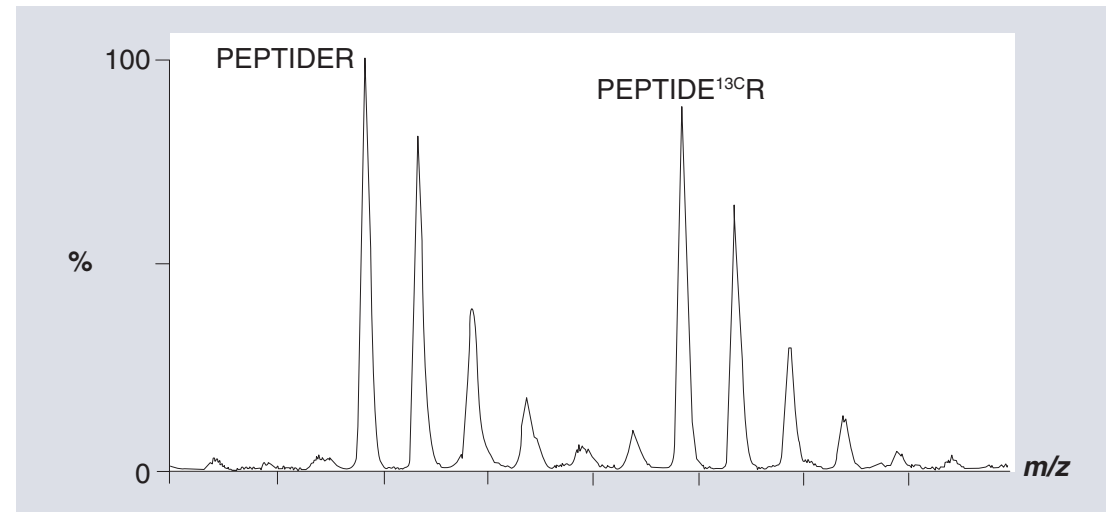

Figure 1. Mass spectrum showing the signals for the analyte PEPTIDER and its ${ }^{13} \mathrm{C}$-labeled analog PEPTIDE ${ }^{13 C} \mathrm{R}$. If the signal for PEPTIDE ${ }^{13 C} R$ were known to be generated by 9 fmoles of material, it would be inferred that there were 10 fmoles of PEPTIDER, assuming that both signals were within the linear range of the instrument response. are generated using the established principle of stable-isotope dilution (SID)-MS [22,23]. This approach involves using an isotopolog of the target analyte as an internal standard (IS). MS is not inherently a quantitative technique due to the differences in ionization efficiency between compounds [24,25]. It is therefore not possible in most instances to determine accurately the absolute amounts of compounds in a sample based upon their signal intensities alone. This is compounded by variations in the efficiency of ionization of a given analyte caused by other compounds in the sample matrix. Such matrix effects may function to either attenuate or enhance ionization efficiency and thus ion signal intensity, such that measurements of this parameter are not necessarily repeatable/reproducible $[26,27]$. To overcome this, a known amount of isotopically labeled standard is added to the sample. The physicochemical properties of the standard and the analyte are identical (bar the differences in elemental composition and thus molecular weight), which leads to equal ionization efficiencies for both compounds. The known amount of added labeled reference hence acts as an internal calibrant that can be used to correlate signal intensity with analyte amount (FIGURE I). As the standard is isotopically labeled, typically using stable-heavy isotopes other than deuterium that can introduce differential chromatographic behavior (see 'Deployment of SRM in quantitative proteomics' section), it is mass resolvable from the unlabeled target analyte and thus they can be co-analyzed without signal interference. Furthermore, the compounds will co-elute from a LC column and thus any effects of the matrix on ionization will be overcome as the signal for both the analyte and the standard will be altered to the same extent. Isotope-labeled standards can also account for losses during sample preparation, as again the analyte and the standard will be affected to the same degree. However, this is not always true in absolute quantitative proteomics where the standard and the analyte are not necessarily in the same state throughout the workflow (see below).

In the area of absolute quantitative proteomics, the precept of SID-MS is applied in the form of surrogacy; the protein is not quantified directly but instead a signature peptide that is released in stoichiometric amounts during enzymatic digestion is quantitatively measured. To achieve absolute quantification, an accurately determined amount of a standard peptide (either as a peptide or as part of a protein) that is an isotopolog of the endogenous analyte of interest is added to the sample as detailed above. The differences between the reported approaches using such isotopically labeled surrogates are in the nature of the standard used. The earliest methods used chemically synthesized peptides containing amino acids enriched with heavy isotopes, for example, ${ }^{13} \mathrm{C},{ }^{15} \mathrm{~N}$ [28,29]; an approach for which the term absolute quantification peptides (AQUA) was recently coined [30,31]. The AQUA peptide can be added either before [32] or after [33,34] the proteolytic digestion step that facilitates excision of the target peptide analyte from its protein environment and allows comparison of the two signals at the peptide level in the mass spectrometer. The peptides selected as reference standards must be unique to the protein of interest and suitable for quantification, that is to say they are 'quantotypic' [35], and hence the amount of peptide is directly proportional to the amount of protein present. Thus, absolute quantification can be achieved. A variation of the AQUA approach is that of the equimolarity through equalizer peptide strategy [36]. This methodology involves chemically synthesizing the isotopically labeled quantotypic peptides (Q-peptides) of interest as dipeptides. A common amino acid sequence is positioned $N$-terminal to the Q-peptide and is referred to as the equalizer peptide. After solubilization and proteolytic digestion, the amount of Q-peptide can be accurately determined through reference to a single light-labeled AQUA peptide. Appropriate amounts of each standard peptide can then be added to a sample of interest (either predigested or prior to proteolysis) to facilitate absolute quantification. An alternative approach 
is implementation of quantification concatemer (QconCAT) proteins [37-40]. In this strategy, a recombinant artificial protein that is a concatenation of the standard peptides from several proteins of interest is heterologously produced in Escherichia coli that is grown in stable isotopically enriched media. The QconCAT protein is then purified by virtue of an affinity tag and co-digested with the sample, generating a stoichiometric mixture of all the 'heavy' Q-peptides of which it is composed, and the proteolytic peptides from the native proteins and IS are subsequently analyzed. A subtle variant of this approach, termed peptide-concatenated standards (PCS), uses flanking regions between the Q-peptides in the artificial protein sequence that mirror their endogenous environment [41]. The final method worthy of mention is the use of protein standards for absolute quantification (PSAQ) [42]. This technique also uses recombinant proteins but rather than being a concatenation of peptides from several proteins, the entire protein to be quantified is expressed in stable isotope-labeled form. One or several PSAQs can then be added to the sample pre-digestion to facilitate quantification.

Each of the strategies mentioned has inherent advantages and disadvantages. AQUA peptides overcome potential issues of completeness of digestion for the standard (the generation of limit peptides for the endogenous analytes still remains a concern however) [43]. Further, limited in-house expertise in the preparation of the standards is required as they can be purchased commercially from several companies. However, this comes at a high financial cost, limiting the possibility of multiplexed experiments. Other potential weaknesses of the AQUA approach include: difficulties in chemically synthesizing some peptide sequences [44] and purifying the reaction products to homogeneity, the need to quantify each peptide standard individually and the difficulty in quantitatively solubilizing lyophilized peptides [45]. The QconCAT approach facilitates multiplexed quantification experiments by obviating the need to handle multiple peptide standards as would be required in a multiplexed AQUA experiment, and decreases the overall financial cost. Furthermore, because QconCAT proteins are designed with an equimolar ratio of all of the Q-peptides, accurate determination of a single quantification peptide facilitates quantification of all others by inference. Finally, sequences intractable by chemical synthesis become available due to the biosynthetic production of the QconCAT protein [46]. One major weakness of the QconCAT approach is that these artificial proteins occasionally fail to express [46]. Another drawback is the possibility for differential efficiency of digestion for the Q-peptide in the standard and the analyte due to their residence in different protein environments. Missed cleavage could lead to inaccurate measurements of levels of protein expression; an overestimate if the analyte is excised to completeness and the standard is not (although this can be easily assessed and the necessary controls put in place); an underestimate if the reverse is true. Whilst the latter is also true for the AQUA approach (because although the standard is by definition a limit peptide, the analyte protein still requires proteolytic digestion to completion), both situations can occur with the QconCAT strategy. However, this weakness in terms of digestability of the standard can be mitigated against by careful design of the QconCAT with reference to bioinformatic tools for missed cleavage prediction [47]. A synthetic protein can therefore be designed that is highly likely to be digested to completeness. Consideration of the protein environment of the Q-peptide in the target analyte is also required so as to favour equalization of digestion efficiencies between the standard and analyte. The PCS approach, which shares many of the advantages of the QconCAT methodology, overcomes the problem of differential proteolysis of the standard and the analyte because, for a given peptide, both the native and reference versions of the Q-peptide are within the same sequence context (generally the $N$-terminal tetrapeptide and the $C$-terminal tripeptide). However, there is evidence to suggest that the optimal size of artificial protein standards for quantification is between $50-70 \mathrm{kDa}$ [35]. Based on this empirical observation, the PCS approach affords a significantly lower level of multiplexing due to the inclusion of the flanking regions within the protein. The PSAQ strategy completely overcomes any problems associated with differential digestion of analytes and standards (excepting any post-translational modificationinduced changes in proteolysis) as the latter is simply an isotopolog of the former. However, the PSAQ strategy again requires quantification of each standard separately, limiting its strength as a multiplexed strategy, increasing costs and decreasing throughput. Further, there is no guarantee that the recombinant version of the protein will occupy the same post-translational 


\section{Key Terms}

\section{Shotgun proteomics:}

A methodological approach for the high-throughput analysis of proteins in a complex mixture. The proteins are digested using a protease, typically trypsin, to generate peptides. The peptides are separated by HPLC and analyzed by MS/MS in a nontargeted manner. Product ion spectra are searched against sequence databases to identify the peptides present in the sample and by inference the gene products from which they originated.

\section{Selected reaction} monitoring: $\mathrm{A} M S / M S$ approach whereby a specific precursor $\mathrm{m} / \mathrm{z}$ value is selected and undergoes dissociation. In the second stage of mass analysis a specific $\mathrm{m} / \mathrm{z}$ value relating to a diagnostic product ion is monitored. The related term of multiple reaction monitoring refers to the parallel monitoring of several product ions from the same precursor ion. state or supramolecular state as the analyte, and therefore equilibrate through the matrix to the same extent, leading to differential behavior during sample processing $[48,49]$.

\section{Application of selected reaction monitoring}

As absolute quantification experiments are typically conducted in a targeted manner towards specific proteins of interest, the operation of the mass spectrometer in these experiments tends to differ from those in traditional nontargeted 'shotgun' proteomic experiments [50,51]. In the latter, MS/MS is usually performed in a 'data-dependent acquisition' (DDA) mode [52], whereby a number of precursor ions generated by the ESI process [53] are selected to undergo ion activation and thus fragmentation, typically by either low-energy collision-induced dissociation (CID) [54], electron-transfer dissociation [55,56] or a combination of both [57,58]. The generated product ions are then mass analyzed to identify, and in some instances quantify, the peptides and thus the proteins from which they originate (FIGURE 2). In most circumstances, the selection of peptides for mass analysis is stochastic, with a user-defined number of precursor ions from a survey scan chosen to undergo ion activation based on their intensities, with the possibility of selecting as many as the 'top 25' with some modern instrumentation [59]. If particular peptides are of interest in the sample then inclusion lists can be utilized to ensure that ions of defined $m / z$ values are selected for mass analysis [60]. Additionally, exclusion lists can be employed to prevent mass analysis of known contaminants [61] in preference to sample-derived components that could yield useful information.

Despite being able to target analytes of interest, shotgun MS/MS experiments are limited in their suitability for absolute quantification proteomics. As the selection of peptides for ion activation is based on intensity, there is an inherent bias towards mass analysis of the more highly abundant peptides, and thus quantification of their constitutive proteins. This bias towards more highly abundant peptides clearly limits the depth to which a proteome can be analyzed, restricting the dynamic range of the analysis to approximately three orders of magnitude [62,63]. To place this in the context of organisms that are commonly examined in proteomic experiments, the simple model eukaryotic organism Saccharomyces cerevisiae (Baker's Yeast) has a proteome that spans about four and a half orders of magnitude $[64,65]$, whilst the Homo sapien (human) proteome is thought to range over approximately eleven orders of magnitude [66] It can be argued that the limitation imposed by the selection of the most intense precursor ions for MS/MS does not prevent quantification of lower abundance peptides. Quantification is achieved using the precursor ion signal in shotgun MS/MS quantitative proteomics experiments, and thus lower abundant peptides can be included in quantitative datasets regardless of whether they have been selected for CID. However, given the complexity of typical proteomics samples, there is a strong likelihood that more than one peptide could account for a given $\mathrm{m} / \mathrm{z}$ value, even when high resolving power mass spectrometers capable of accurate mass measurements are used [67]. Therefore, to allow confident identification, and thus quantification, MS/MS is required to allow the sequence of the peptide to be determined, meaning that intensity-based precursor ion selection will limit the dynamic range in shotgun MS/MS quantitative experiments. Another drawback of shotgun proteomics experiments is the stochasticity of the selection of precursor ions for MS/MS. This can lead to inconsistent datasets for similar samples if the same peptides are not selected during the first stage of mass analysis in different experiments, potentially limiting the ability of a study to investigate the proteins of interest. Software processing tools that overcome this limitation by applying peptide identifications from one LC-MS/MS analysis to identify precursor ion signals in the survey scan of an independent LC-MS/MS acquisition have been reported. The signal intensities of these peptide ions in the survey scan can then be used for quantification. However, this approach requires high-resolving power LC-MS instrumentation capable of the acquisition of accurate mass retention time datasets [67] to allow the matching of signals between data files, and such instrumentation tends to come at high financial cost. Furthermore, this approach suffers from the implicit need to analyze the same sample multiple times, which increases the necessary instrument time and may not always be possible under sample-limited conditions $[68,69]$.

The issue of incomplete datasets due to stochasticity is especially problematic when two substantially different biological samples are being compared, for example, cells grown under different conditions. If a protein(s) of interest is significantly downregulated in one sample 
relative to the other, such that its constituent peptides are no longer selected for mass analysis due to a decreased intensity in the survey scan, then potentially useful information is sacrificed. Thus, the dataset will be incomplete and the comparison of a given protein's behavior between different conditions will not be possible. The final weakness of data-dependent shotgun proteomics is that the instrument platforms used to conduct the experiment suffer from low duty cycles, that is to say the percentage of time a mass analyzer spends transmitting ions of a particular $m / z$ during one experimental cycle [70]. The typical shotgun MS/MS experiment is a product ion analysis approach, whereby precursor ions are dissociated and the product ions so formed are detected. These experiments are generally performed on either quadrupoleorthogonal axis time-of-flight (Qq-oaTOF) [71] or ion trap (IT) (both 3D [or QIT] [72,73] or linear [LIT] [74,75]) mass spectrometers. Even though significant advances have been made in these technologies in recent years, they still suffer from a relatively low duty cycle when operated in a data-dependent product ion mode and coupled to a continuous ionization technique [63]. Whilst both instruments are conducting mass analysis, compounds eluting from the column will not be analyzed. This means that an IT instrument has an overall duty cycle of a few percent depending upon how the experiment is conducted and whether it is a $3 \mathrm{D}$ or linear mass analyzer [76]. A Qq-oaTOF mass spectrometer is also unable to acquire data $100 \%$ of the time during the second stage of mass analysis because the flight tube has to be cleared of one packet of ions before the next can be admitted, resulting in a duty cycle of approximately 5-30\% [71,77]. Given the high complexity of many proteomic samples, the low duty cycle of a shotgun MS/MS experiment leads to lost information because the mass spectrometer can not scan sufficiently quickly to mass analyze all of the peptides eluting from a HPLC column [78].

To overcome the described limitations of shotgun MS/MS, the mass spectrometric approach of selected reaction monitoring (SRM) can be implemented (the term multiple reaction monitoring is often used to describe the

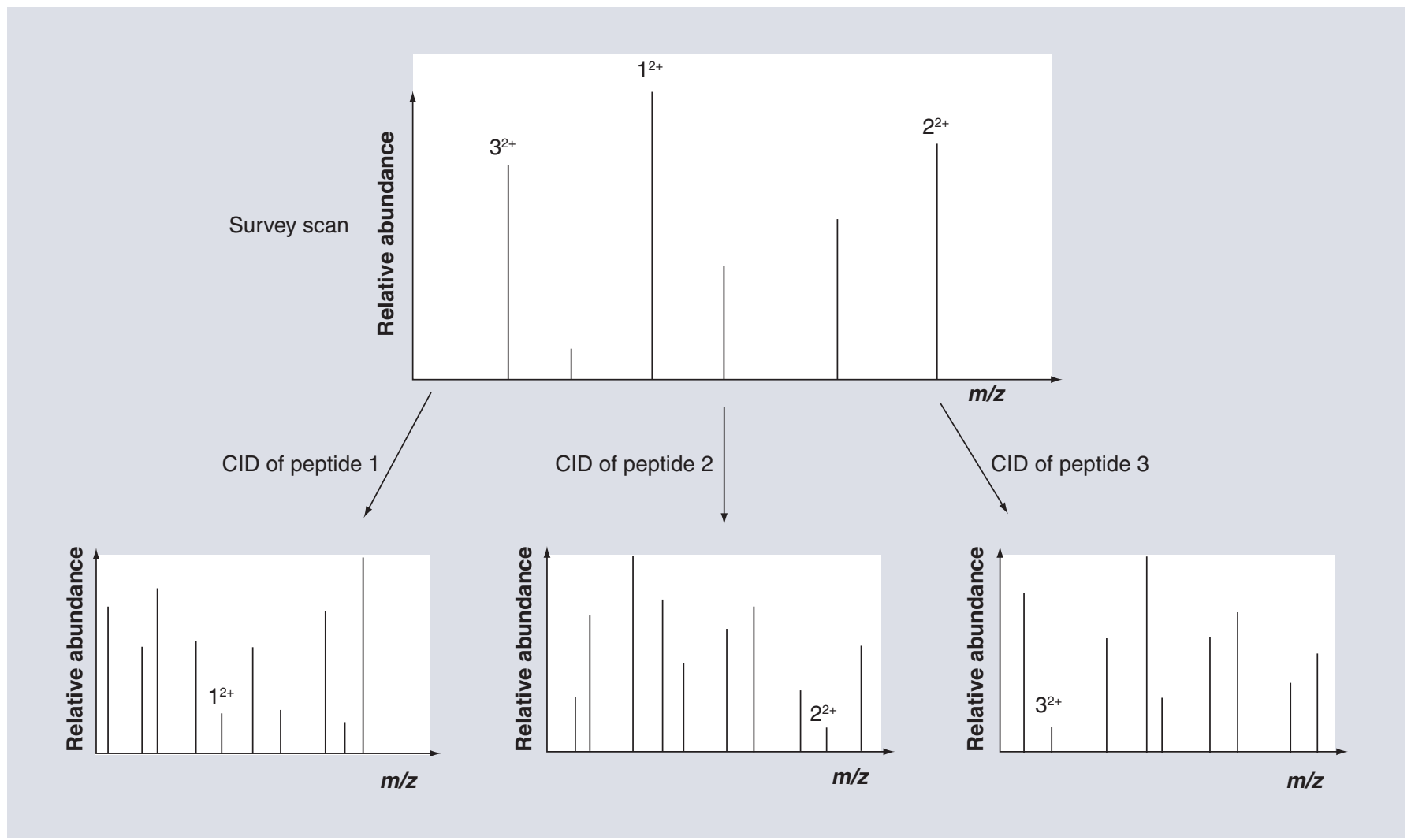

Figure 2. Representation of the operation of a mass spectrometer in a data-dependent experiment. In this example, the top three most intense peptides are selected to undergo low-energy CID, with the product ion analysis conducted in a serial manner. CID: Collision-induced dissociation. 
parallel monitoring of more than one product ion from a given precursor) [79,80]. Whilst this methodological approach is not new and has been used extensively for small-molecule analysis for several decades $[81,82]$, it is only within the last few years that the strategy has begun to find application in the area of quantitative proteomics. SRM is a targeted mass spectrometric approach that is typically applied on tandem quadrupole mass spectrometers (QqQ) (the term triple quadrupole is often used, but does not accurately reflect many modern instruments that use devices other than quadrupoles as the collision cell) (FIGURE 3) [83-85]. Pseudo-SRM experiments can be performed on other MS/MS platforms such as LIT [86-88] and Qq-oaTOF [89] mass spectrometers, typically with reduced multiplexing capabilities due to their low duty cycles. In a SRM experiment, the QqQ mass spectrometer is not operated in a scanning mode (FIGURE 3). Instead, the first quadrupole mass analyzer is set to admit a single $m / z$ value to the collision cell, which in a quantitative proteomics experiment will be the $m / z$ value of an ionized peptide of interest. After low-energy CID of the precursor ion(s) admitted to the collision cell, only a specific product ion will have a stable trajectory to the detector as the second quadrupole mass analyzer is also fixed on a single $m / z$ value. This $m / z$ value is set to that of a diagnostic product ion from the precursor of interest. The combination of two $\mathrm{m} / \mathrm{z}$ values relating a product ion with that of its precursor is referred to as a 'transition'. The two levels of $\mathrm{m} / \mathrm{z}$ selection provide the advantages of SRM: high selectivity, low background signals and high duty cycle. For a peptide to be detected it needs to satisfy, as an intact ion, the $m / z$ value that the first quadrupole is set to, and then generate a product ion with an $\mathrm{m} / \mathrm{z}$ value such that it will be stable in the second quadrupole mass analyzer. Therefore, even if two peptides co-elute from an HPLC column and have sufficiently similar $m / z$ values as ionized species, to have stable trajectories through the first quadrupole, they can be discriminated by virtue of differences in their gas-phase ion chemistry under low-energy CID conditions, as only defined product ions will reach the detector. This selective analysis leads to a reduction in background signal, and thus an increase in signal-to-background ratio, as fewer ions relating to interferences will reach the detector. A corollary of the increased signal-to-background ratio and of the near $100 \%$ duty cycle is that the dynamic range of a SRM experiment exceeds that of a data-dependent experiment. This is because lower abundance analytes can be differentiated from the background signal, extending the dynamic range to between four-to-five orders of magnitude [90]. Further, increased signal-to-background ratios can convert signals unsuitable for quantification into ones that provide reliable quantitative data [91]. The ability to detect analytes across a wide dynamic range with a high degree of selectivity has been a prime driver for the application of SRM in proteomics, where proteins of interest may be at a wide variety of expression levels in very complex mixtures.

As briefly mentioned above, another advantage of SRM is that it allows the duty cycle of the experiment to be increased to almost 100\% (a small percent of the experiment is still not spent acquiring data for the ions of interest because of the interscan delay required to clear the collision cell of ions before the next dissociation event). The tandem-in-space nature of

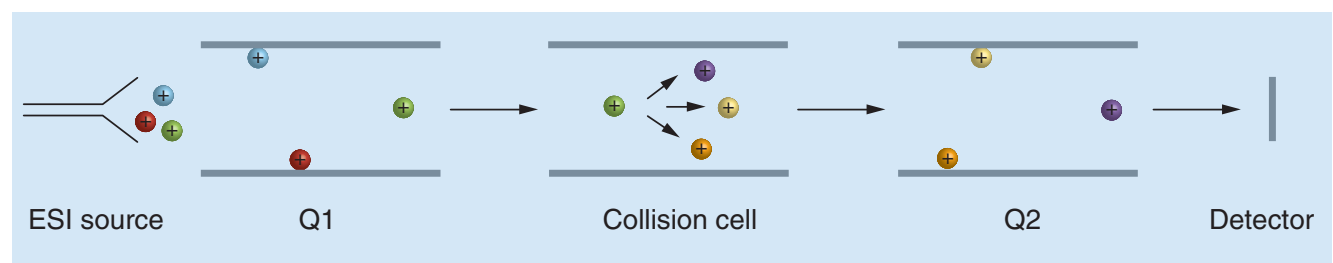

Figure 3. Representation of the operation of a mass spectrometer in a selected reaction monitoring experiment. The first quadrupole mass analyzer (Q1) is set to only allow the $\mathrm{m} / \mathrm{z}$ value corresponding to the green precursor ion to have a stable motion within the electric fields, thus filtering out the blue and red precursor ions that have different $\mathrm{m} / \mathrm{z}$ values. The green precursor ion is then subjected to low-energy CID in the collision cell and the product ions directed to the second quadrupole mass analyzer (Q2). Q2 is also set to only allow a single $\mathrm{m} / \mathrm{z}$ value to have a stable motion, which allows the purple product ion through the quadrupole whilst removing the orange and yellow product ions that have different $\mathrm{m} / \mathrm{z}$ values. Thus, the purple product ion can reach the detector and generate a signal.

CID: Collision-induced dissociation. 
the tandem quadrupole instrument, coupled with the transmission of ions at specific $\mathrm{m} / \mathrm{z}$ values rather than a requirement to perform a scanning analysis, means that the ion beam generated from a continuous ionization source can simply be filtered to monitor the predefined combinations of precursor and product ions of interest by changing the voltages applied to the quadrupoles. The electronics of modern instruments facilitate extremely rapid voltage changes, and hence almost instantaneous switching from the monitoring of one transition to the next. As the duty cycle is high, and because the experiment is targeted, the SRM approach is highly efficient. Such efficient usage of instrument time means that highly multiplexed analyses are possible, both in terms of the number of analytes targeted and the product ions monitored, with greater numbers of the latter increasing the selectivity for the former (see 'Deployment of SRM in quantitative proteomics' section). Importantly, with respect to multiplexed analyses, the high duty cycle also means that data can be acquired for analytes that co-elute from the HPLC column, even when they differ significantly in concentration - a critical limitation of data-dependent shotgun-based quantitative analysis. Focusing the instrument on analytes of interest also allows the dwell time (i.e., the time the instrument spends recording data for a given $\mathrm{m} / \mathrm{z}$ value before moving onto the next) to be maximized. Longer dwell times improve ion statistics and thus signal-to-background ratio, resulting in higher quality data that facilitates more accurate and precise quantification. Further, it enables low abundance peptides to be detected because more instrument time is spent attempting to detect the analytes of interest compared with that in a shotgun proteomics experiment. Therefore, there is a greater chance of recording the fewer ions generated from minor components of a sample.

Whilst the development of a SRM experiment requires a significant investment of time to design optimal coordinates for the peptides under consideration, the preprogramming of the mass spectrometer to record relevant information throughout the experiment means that the acquired datasets are repeatable/reproducible and complete, that is to say an analyte of interest will not be missed because of the targeted nature of the experiment $c f$. the stochastic sampling in a DDA experiment [92]. This generation of holistic datasets with quantitative values for peptides, and thus the proteins for which they act as surrogates, across several orders of magnitude makes the SRM approach optimal for the generation of input data for mathematical modeling in systems biology.

\section{Deployment of SRM in quantitative proteomics}

The targeted nature of SRM means that the peptides to be analyzed must be defined prior to analysis. There are many factors that need to be considered in the selection of appropriate peptides to report on the proteins of interest. First, the peptides need to be diagnostic markers for the specific protein, meaning that they should be unique within the proteome of interest. Importantly, consideration should also be given to likely contaminant proteins in the sample preparation, for example keratin. Once a candidate list of peptides has been generated, the decision as to whether qualitative or quantitative information is required needs to be made. If qualitative information is required, the list of suitable peptides is more extensive. In this circumstance, proteotypic peptides are suitable [93]. Proteotypic peptides are defined as those peptides that unambiguously represent a given protein and are consistently observed in MS experiments. A list of such peptides, with associated transitions, has been published by Picotti and coworkers and is publicly available via the SRMAtlas project website [94,201]. However, proteotypic peptides may not be formally quantitative. For example, the peptide QEGDEIMEGITLER is a proteotypic peptide for tRNA-splicing endonuclease subunit SEN34 in the proteome of $S$. cerevisiae. However, methionine residues are known to be susceptible to artefactual in vitro oxidation during sample preparation [95,96]. There is no guarantee that the level of oxidation will be equal in the standard and the analyte, and also no reliable method of assessing the extent of oxidation. Comparison of the signal generated by the analyte to that of the standard may thus not give an accurate quantitative value of the abundance of the native peptide, and hence the protein from which it derives. Further, $N$-terminal glutamine can cyclize to generate pyroglutamate [97,98], again in a potentially nonequal ratio for the standard and the analyte, further compromising the quantitative value garnered using this peptide. Finally, the example peptide has glutamic acid residues in positions $\mathrm{P} 2$ ' and $\mathrm{P} 2$ relative to the $\mathrm{N}$ - and $C$-terminal tryptic sites, respectively (position designations based on the Schechter and Berger 
nomenclature [99]). Acidic residues close to the tryptic site have been shown to promote missed cleavage [47]. Absolute quantification relies on the generation of limit peptides for accurate assessment of protein expression due to differences in nature between the analyte and the standard (where the equality of missed cleavage can not be assumed). Any residues or sequence motifs that disfavor complete proteolysis are thus likely to compromise the quantitative data. Therefore, in cases where absolute quantification is required, the use of $\mathrm{Q}$-peptides rather than proteotypic has been advocated [35]. Q-peptides have all of the characteristics of proteotypic peptides but also place restrictions on the residues that can constitute the peptide to eradicate artefactual modification and/or incomplete cleavage, hence making the peptides formally quantitative of the proteins for which they report on. The features of Q-peptides and their rationale are briefly outlined in TABle $\|$. A more detailed consideration of the factors important in the selection of Q-peptides has been discussed by Brownridge and coworkers [35]. Ideally, Q-peptides that have previously been observed in MS-based experiments, determined by reference to publicly available databases [100103], should be used to give a high likelihood of detection. However, for low abundance proteins against which there is bias in shotgun proteomics experiments, upon which these databases are typically based, or for organisms for which little publicly available data is available for reference, computational prediction of suitable peptides can be employed. Several such prediction tools have been reported in the literature (PeptideSieve [104], Enhanced Signature Peptide predictor [105] and CONSeQuence [106]) and suggest peptides that are likely to be detected by MS based upon their physicochemical properties.
Once suitable peptides have been selected, the design of optimal SRM 'co-ordinates' needs to be addressed. A SRM co-ordinate involves four pieces of information: the precursor ion-charge state to monitor for a given peptide; the $\mathrm{m} / \mathrm{z}$ of the product ion generated by low-energy CID of the precursor; the collision energy required to effect dissociation of the precursor and generate optimal signal intensity of the product; and the retention time of the peptide under the chromatographic conditions employed to facilitate scheduled acquisition. Once these SRM co-ordinates have been defined for a specific peptide, they can be readily exported and adapted for use on other tandem quadrupole instruments [94,107,108].

The choice of the precursor ion charge state and product ion(s) to monitor, specifically the transition(s), for a given peptide can be determined by a variety of means. First, bioinformatic prediction can be employed using both open source and commercially available tools [109-111]. These programs are generally built upon empirical observations about peptide behavior under ESI (e.g., tryptic peptides generate doubly-charged precursor ions, except for histidine-containing sequences where the additional basic site provided by the side chain facilitates the production of triply charged ions) [112] and low-energy CID conditions (e.g., favored peptide backbone cleavage $N$-terminal to proline) [113-115]. These tools tend to provide a good starting point for SRM co-ordinate design but, in the authors' opinion, the incomplete understanding of peptide behavior under ESI and lowenergy CID conditions makes reliance on these tools somewhat precarious. Instead, recourse to experimental data is advocated to ensure the design of high-quality, reliable transitions. This

Table 1. Properties of quantotypic peptides and rationale.

\section{Property}

Unique amino acid sequence

No reactive residues e.g., methionine and $N$-terminal glutamine

No $N$ - or C-terminal peptides

No sites of known or putative post-translational modification

No dibasic context

Not susceptible to missed cleavage

\section{Rationale}

Ensures that peptide is diagnostic for a single protein

Susceptible to artefactual modification during sample preparation, which may not necessarily be equal between standard and analyte

Sequences in the native proteins are susceptible to degradation

Prevents the surrogate peptide from being in equal stoichiometry to the parent protein

Dibasic motifs, up to and including BxxxB (where $B$ is an arginine or lysine residue and $\mathrm{x}$ is any other amino acid residue) can lead to non-stoichiometric proteolysis of the target peptide [43]

Prevents stoichiometric release of the peptide from the native protein and protein-level standard

Enables the targeted peptides to be detected 
data can be obtained by a number of means. First, SRMAtlas contains validated transitions for peptides from the proteomes of $S$. cerevisiae, H. sapien and Mus musculus [94]. However, to date, this database does not include all of the proteotypic and Q-peptides for these proteomes and is limited in respect of the organisms that it covers. Despite these limitations, it is arguably the best existing resource for selecting transitions for the peptides in the database due to the fact that the product ion spectra used to populate it have been acquired on a collision celltype instrument, which profoundly affects the acquired low-energy CID mass spectrum (see below). Experimental data can also be generated in-house, with methodologies reported for the rapid generation of reference peptides from which to obtain product ion spectra [116,117], or sourced via publicly available product ion spectral libraries generated from shotgun proteomics experiments [118-120]. These repositories are likely to give reliable reflections of the favored precursor ion charge state of the peptide at a given level of sample complexity. However, caution needs to be exercised in the selection of product ions to monitor. The vast majority of publicly available product ion spectra have been acquired on IT mass spectrometers that perform on-resonance excitation low-energy CID [121]. Under these conditions, it has been demonstrated that the stability of b-type sequence ions $[122,123]$ is much greater than when the same peptide is dissociated using non-resonant low-energy CID excitation in a collision-type instrument [124]. Therefore, b-ions, particularly higher order members of the series, will be more prevalent in IT spectral libraries than in corresponding product ion spectra acquired on collision cell instruments, such as tandem quadrupole mass spectrometers. Thus, b-ions should be disfavored in SRM assays designed using product ion spectral libraries, unless further experimentation is performed to confirm that the fragment is observed with high intensity on a collision cell instrument. The stability of y-ions is far better conserved between lowenergy CID approaches and therefore such ions represent much better candidates for the design of transitions. Further, it has been demonstrated that, at least for doubly charged tryptic peptides, the rank order of product ion intensities is well correlated between IT and tandem quadrupole platforms $[119,125]$. This is particularly pertinent as it is advantageous to monitor product ions that produce the most intense signals upon dissociation as the LOD and LLOQ are lowered as a result. It could be argued that this is not necessarily the best strategy for selecting product ions to monitor, as favoring signal intensity at the expense of selectivity can lead to the potential for false positives in complex mixtures [126]. However, the likelihood for false-positives is extremely difficult to predict a priori, as this will depend upon the abundance and propensity to ionize interfering species with the same precursor ion $m / z$ value as the peptide of interest (NB: the interfering species may not necessarily be peptidic in nature, but could also be other biological materials present in the sample), and the chromatographic conditions utilized, which will govern whether elution of the interfering species will coincide with the time during which a given transition is monitored (see below).

As a result of this difficulty in predicting selectivity of transitions, arguably the best approach is to monitor the most intense product ions of greater $m / z$ value than the precursor ion. Under these conditions, co-eluting singly charged interfering ions that are co-isolated using the first quadrupole are filtered out by the second because they can not generate a product ion of greater $\mathrm{m} / \mathrm{z}$ value. Thus, the interference is removed and the selectivity of the assay is increased. Increased discrimination can be achieved by monitoring several transitions per peptide, and this strategy is strongly advocated. However, this can come at the expense of the capability to perform multiplexed experiments, as only a finite number of transitions can be monitored whilst maintaining dwell times that achieve acceptable signal-to-background ratios and allow sufficient points across the chromatographic peak to describe its shape accurately (typically considered to be at least 10 ; see below) [91]. Typically, monitoring three-to-four transitions per peptide gives a suitable balance between selectivity and throughput $[92,127,128]$.

An alternative and improved strategy to using public repositories of tandem mass spectra to design SRM transitions may become available in the near future. de Graaf and coworkers recently demonstrated that the correlation in both qualitative and quantitative terms between product ion spectra acquired using QqQ-MS is greater when compared with those obtained on an Orbitrap mass spectrometer [129] using higher energy collision dissociation (HCD) [130] than those recorded on IT mass spectrometers for both doubly and triply charged tryptic peptides [131]. With the increasing usage of Orbitrap 
mass spectrometers in shotgun proteomics experiments due to improved performance in terms of scan speed and duty cycle [132-134], it is likely that significant numbers of HCD spectra will become available in public repositories over the next few years. As the product ion spectra generated using HCD Orbitrap-MS appear to reflect peptide fragmentation using low-energy CID QqQ-MS more accurately than those obtained by low-energy CID IT-MS, less optimization will be required when designing SRM transitions from publicly available data.

Once product ions suitable for monitoring have been selected, the optimal collision energy required to effect dissociation of the precursor ion, and thus maximize the intensity of the chosen product ions, needs to be determined. As a starting point, most manufacturers provide a linear regression, specific to a precursor ion charge state, expressed as:

$$
\text { Collision energy }=\mathrm{a} \times m / z+\mathrm{b}
$$

The use of a collision energy determined by such equations gives a degree of dissociation that is sufficient to detect the product ions of interest [135]. However, further optimization of collision energies can maximize product ion intensities because optimal collision energy does not scale linearly with $m / z$ ratio for peptide ions; it has been demonstrated that instead it varies with degrees of freedom, for which $\mathrm{m} / \mathrm{z}$ is merely a proxy [136-138]. There is, however, conflicting evidence in the literature as to the extent of improvement of signal intensities that can be obtained through collision energy optimization. Picotti and coworkers found that for a set of 96 peptides where the four most intense product ions were monitored, improvement of less than 1.5-fold in signal intensity was achieved for $72 \%$ of transitions. In $91 \%$ of cases, below a threefold increase was obtained by optimizing collision energies [116]. This suggested that the linear regressions recommended by the instrument manufacturers are generally suitable for predicting near-optimal collision energies and that only in cases where maximizing signal intensity is crucial to the success of the experiment; for example, to detect low abundance peptides, is there value to performing collision energy optimization for a SRM assay.

Maclean and coworkers observed somewhat contradictory results using a tryptic digest of a six protein mixture, from which four transitions were monitored for 20 doubly charged and 10 triply charged peptides [139]. This study determined that the recommended linear regressions were suboptimal for a range of tandem quadrupole instruments from different manufacturers, and that recalculation of the linear equations for each individual charge state was necessary to obtain optimal signal intensities. Post-recalculation of the linear regressions, significant improvements in signal intensity were made for triply charged peptides, with a less pronounced but nonetheless observable increase for doubly charged peptides on all but one of the instruments used. The study also showed that only a very modest increase of on average $7.8 \%$ was obtained through optimizing the collision energy for each precursor ion individually compared with using the value predicted by the optimized linear regression. Therefore, whilst reoptimization was required, this recalculated linear regression proved very successful at predicting optimal collision energies for peptides other than those used to establish the equation. This group also found that optimizing collision energies for each transition specifically, rather than on a precursor ion-by-precursor ion basis, obtained a minimal improvement in signal intensity, and that the gain made would be insignificant at low abundance due to the levels of shot noise. The only case that benefited significantly from individual collision energy optimization was a triply charged ion where the products monitored were a doubly charged y-ion and two singly charged b-ions. This suggested that optimized linear regressions using predominantly singly charged y-ions, as is common practice, poorly predict the best collision energy for other product ion types and/or charge states. The findings of the Maclean et al. study were consistent with the observations of Sherwood and coworkers, who performed collision energy optimization on a per peptide basis for 22 triply charged tryptic peptides [140]. For the 90 singly charge y-ions monitored, $59 \%$ of transitions saw an increase in intensity of more than $30 \%$ compared with using the default equation-predicted collision-energy. This corroborated the findings of Maclean and coworkers in the respect that recalculation of the linear regression for collision-energy prediction is required for each precursor ion charge state. However, the two studies are in disagreement as to the extent of the signal intensity gains that are achieved after optimization. The final major study to date of collision energy optimization was performed by Holstein and coworkers, where 80 doubly charged tryptic peptides were considered [141]. This group monitored a total of 844 singly charged product ions split into three categories 
based on fragment type: b-ions, y-ions and $\mathrm{D} / \mathrm{E}-\mathrm{X}$ ions, specifically those products generated through cleavage $C$-terminal to an aspartic and glutamic acid; a favorable fragmentation pathway under low-energy CID conditions [142-144]. The study established, through optimization of signal intensities on a per-transition basis, that b-ions require lower collision energies than y-ions to produce optimal signal intensities; whilst product ions generated through D/E-X cleavages require a higher collision energy. The decrease in signal intensity when using the default collision energy compared with the optimized one was most significant for b-ions, with an average reduction in ion current of over $50 \%$. The loss was less acute for $\mathrm{D} / \mathrm{E}-\mathrm{X}$ and $\mathrm{y}$-ions, which saw reductions in signal intensity of $19 \%$ and $6 \%$, respectively. Although optimization of the collision energy was shown to significantly increase the signal intensities of the b-ions, they still did not rank amongst the most intense peaks for the majority of peptides after refinement on a per-transition basis. Therefore, this study supports the consensus view that $y$-ions are favorable product ions to monitor in a SRM assay, although the authors did demonstrate cases where selecting the next most intense y-ion in preference to a b-ion would result in the sacrifice of a non-negligible percent of signal. Further, using these optimized collision energies the authors established two new linear regression equations for each product ion type, as well as two further equations based on all of the transitions. The first equation in each case took into account only the precursor $\mathrm{m} / z$ value, whilst the second included the dependence of the collision energy on product ion $\mathrm{m} / \mathrm{z}$ value. The authors demonstrated that inclusion of the product ion $\mathrm{m} / \mathrm{z}$ value facilitated closer prediction of the optimal collision energy, as evinced by the higher coefficient of determination for the regression lines for each product ion type. They also showed that the predictive equations for the three product ion types differed from one another, underlining the value of considering the effect that gas-phase ion chemistry and structure can have on optimal collision energy values. Finally, amalgamation of all of the transitions to allow a direct comparison to the default equation demonstrated a disparity to the linear regression provided by the instrument manufacturer - a recurrent theme of the cited studies.

Given the relatively small sample sizes considered in the cited studies (relative to the chemical space covered by the complex proteolytic digests encountered in proteomics experiments), the conflicting results of the cited studies are arguably not unsurprising. As a general rule, the existing literature suggests that the linear regressions provided by the manufacturers for their particular platform can vary on an instrument-by-instrument basis, and thus recalculation is recommended. This recalculation should be cognisant of the fact that doubly and triply charged tryptic peptides require different linear regressions and thus should be considered separately. A single calculation of the linear regression is then sufficient to obtain an equation that can predict a near-optimal collision energy for any given peptide and transition, which is particularly pertinent if high-throughput is required and little time can be devoted to assay refinement. However, if detection to very low levels is required, and if time allows, then optimization of collision energy, particularly on a per-transition basis, can afford better quality data at the expense of decreased throughput.

The final property of a given peptide to establish is its retention time. This aspect of a SRM co-ordinate can be viewed as optional, although its inclusion significantly enhances multiplexed and/or high-throughput experiments as it facilitates a strategy referred to as 'scheduled SRM' $[145,146]$. The approach involves only monitoring the transitions for a specific peptide in a time window around its expected elution from the HPLC column. Such scheduled SRMs have two notable advantages: improved data quality and the ability to significantly increase the number of peptides targeted in a single LC-MS analysis. As discussed above, precise quantification requires a sufficient number of data points to be recorded across the elution profile of a peptide to describe its shape satisfactorily. Whilst there is some conjecture as to the number of data points required to accomplish adequate description of a chromatographic peak, with some studies using as few as five-to-six data points [147,148], it is generally accepted that at least 10 points-per-peak is the minimum [91]. Given that peak widths of peptides separated using reversed-phase nano-HPLC with elution gradients suitable for quantification (normally between 30-60 min) are in the region of 15-30 s, and generally dwell times of at least $20 \mathrm{~ms}$ are necessary to obtain acceptable signalto-background ratios for even moderately abundant analytes (longer dwell times being required for peptides of lower abundance), the number of co-eluting peptides that can be detected with sufficient points across the peak is limited [65]. For example, if a peptide elutes over $15 \mathrm{~s}$, a data 


\section{Key Term}

Repeatability: A measure of the precision obtained when a method is repeated under the same conditions, specifically same operator, equipment and reagents, with measurements made within a short period of time. point must be recorded every $1.5 \mathrm{~s}$ to achieve 10 points across the peaks (the time between the recording of one data point and the next for a given peptide is referred to as the 'cycle time'). If a dwell time of $50 \mathrm{~ms}$ is required (including the interscan delay), then this equates to 300 possible data points across the peak. Therefore, if 10 data points are required for every peptide, a total of 10 co-eluting peptides with three transitions monitored for each can be targeted over this $15 \mathrm{~s}$ time frame. If a nonscheduled strategy were pursued, then only these 10 peptides could be analyzed in a single LC-MS analysis (Figure 4A). However, by scheduling the relevant transitions around the elution time for the peptide that they relate to, more efficient use of the cycle time can be achieved. Either an increase in dwell time per transition can be realized, thus improving the signal-to-background ratio due to an averaging of the shot noise over a longer timeframe, or a greater number of transitions can be monitored, allowing more peptides to be targeted in a given experiment and/or more product ions to be recorded for each analyte, hence increasing the selectivity of the assay (FIGURE 4B). Furthermore, knowledge of a peptide's retention time increases the selectivity of the assay. This is because chromatographically resolved signals can be differentiated as arising from the target peptide or biological noise based upon the analyte's known elution time. Scheduling can be performed using one of a variety of retention time predictors that are available [149-155]. However, given the current limitation of such predictors, with predicted retention times often differing significantly from experimental observations [156] and the current lack of tools available for adequate retention time calibration for a given HPLC system, at present accurate scheduling is best achieved following empirical determination on the specific platform (instrument and columns) to be used for the targeted analysis (slight difference in path length on different HPLC systems can have profound effects on peptide elution times, particularly at the nano-scale flow rates typically employed in proteomic analyses). Ideally, peptide elution times should also be determined in the matrix that will be used, as different sample composition and concentration can have an effect on the retention time of a given compound, presumably due to differential ion-pairing effects [157]. If the retention time for a peptide is established in a dissimilar matrix to that in which it will be ultimately analyzed, there is a risk that the scheduling will be erroneous. Thus, data for that peptide will be lost in the quantification experiment as the monitoring of its transitions will no longer coincide with its elution from the HPLC column. Further, successful implementation of scheduled SRM analyses requires high repeatability of peptide retention times on the HPLC instrument used to prevent elution of the analytes outside of the scheduled time windows during an analytical run.

Once the SRM co-ordinates have been determined, a decision must be made as to the number of these to combine to constitute the final assay for a given peptide. As mentioned above, it has been shown that three-to-four transitions per peptide gives a satisfactory balance between data quality and throughput, especially when scheduling is invoked, and allows the identification of contaminated channels due to co-eluting interferences whilst leaving 'clean' chromatograms to be used for the downstream data processing $[127,128]$. This relatively low number of product ions per peptide is in part enabled by the fact that absolute quantification experiments utilize a stable-isotope-labeled IS. This not only enables comparison of relative product ion intensities to facilitate confident identification, but also generates corroborative evidence in the LC space as the standard co-elutes with the analyte (assuming that deuterium is not employed as the stable-isotope label) [158-160]. Therefore, as complementary information is obtained by orthogonal analytical techniques based on different properties of the peptide, fewer product ions need to be monitored to mitigate against false positives when a stable-isotope-labeled reference peptide is present in the sample [128].

An alternative novel approach to improving selectivity called intelligent SRM (iSRM) has been recently reported [161]. This strategy involves monitoring the primary transitions for a peptide, which when observed trigger the acquisition of a secondary set of transitions. From the two sets of transitions, a composite product ion spectrum for the peptide is constructed. This spectral information can be searched against a suitable database to confirm the presence of the peptide of interest, thus reducing false-positive quantification. iSRM, therefore, enables accurate and precise description of the peptide's elution profile for quantification and the acquisition of a composite product ion spectrum for identification without sacrificing dwell times due to monitoring a high number of transitions per peptide. The drawback of this approach is that it is currently only available on one vendor's tandem 
(A)

Eile Edit Wiew gptions Ioolbars functions Help

口遂回最

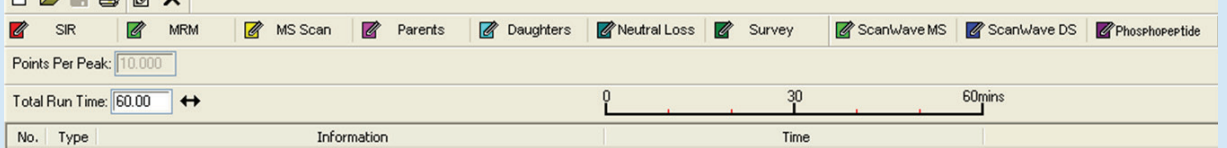

\begin{tabular}{|l|c|c|}
\hline No. Type & Information & Time \\
\hline
\end{tabular}
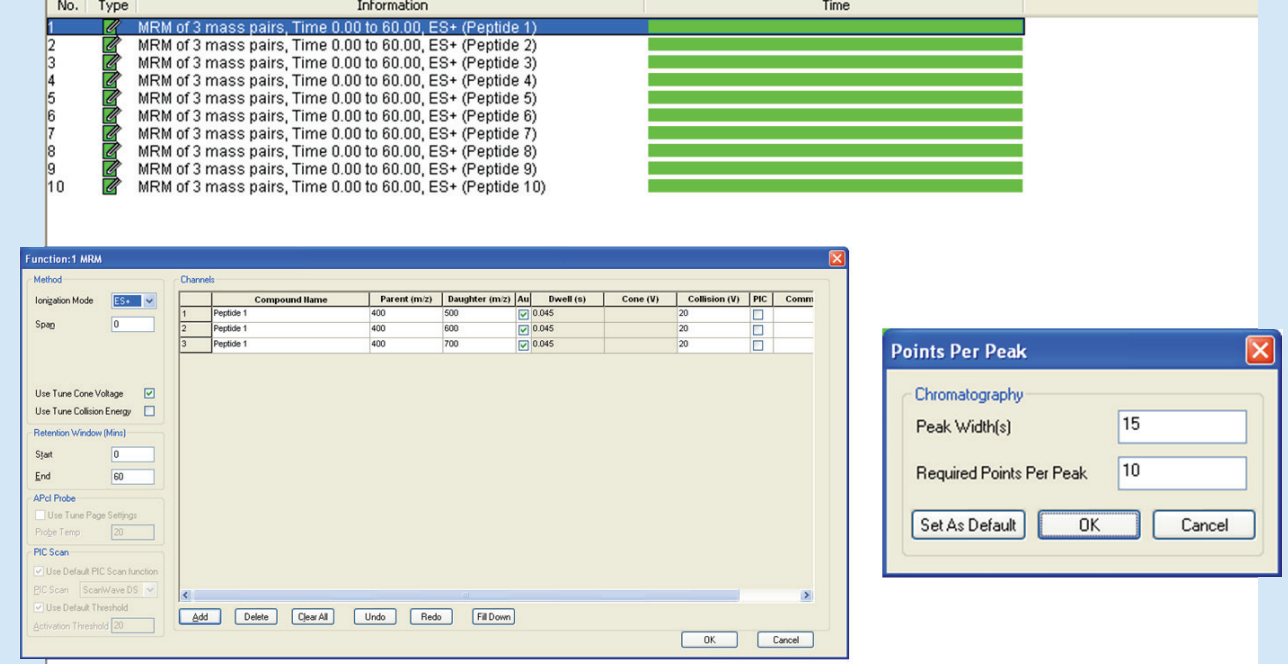

(B) Elie Edit view options Ioolbars Functions Help

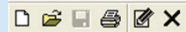

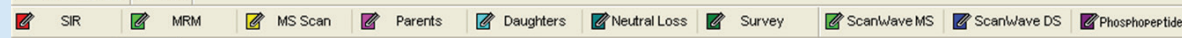

Points Per Peak: 10.000

Total Run Time: $44.75 \leftrightarrow$

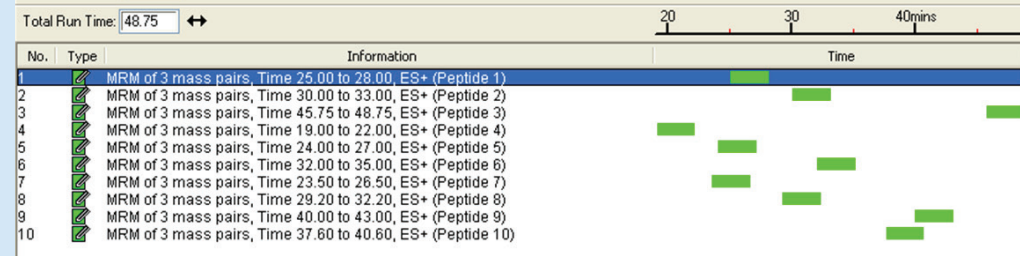
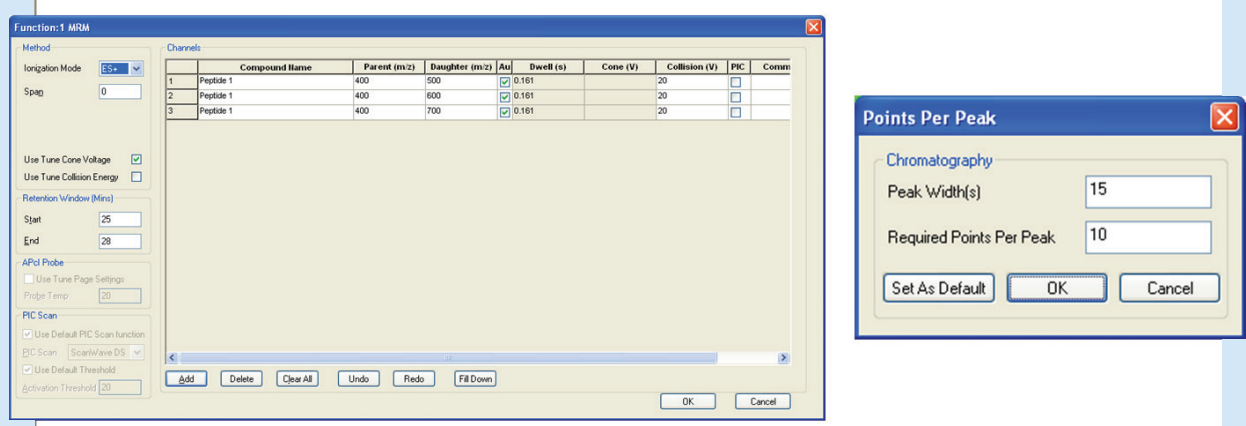

Figure 4. Comparison of dwell times for unscheduled and scheduled selected reaction monitoring methods. (A) An unscheduled selected reaction monitoring (SRM) method with peak width set to $15 \mathrm{~s}$ and 10 points-per-peak stipulated. Under these conditions, a dwell time of $45 \mathrm{~ms}$ for each transition is achieved (NB: dwell time does not include 5 ms interscan delay per transition) (screenshots taken from MassLynx 4.1 SCN 714 [Waters, UK]). (B) A scheduled SRM method targeting the same peptides as the method in (A), with peak width set to $15 \mathrm{~s}$ and 10 points-per-peak stipulated. Under these conditions, the dwell time per transition is significantly increased, which will lead to an improvement in data quality. Alternatively, more transitions (either more peptides with three transitions or greater than three transitions per peptide) could be monitored per unit time with a dwell time equal to that achieved in the unscheduled SRM method, thereby increasing throughput or confidence in identification, respectively (screenshots taken from MassLynx 4.1 SCN 714 [Waters, UK]). 


\section{Key Term}

False discovery rate:

A measure of the number of false positive assignments within a dataset. The false discovery rate is typically expressed as a percent of all accepted data. quadrupole platform. However, it is anticipated that other instrument manufacturers will implement similar strategies in the future to reduce false-positive results in quantitative proteomics experiments, which are a significant risk due to the high complexity of the samples analyzed.

\section{Processing of SRM data from multiplexed experiments}

One of the biggest challenges to date in the implementation of large-scale SRM-based quantitative proteomics experiments has been the processing of the acquired data. To a large extent, this has hitherto been a manual endeavor, with the inherent limitations that analyst interrogation of data brings, including time consumption, subjectivity, inconsistent application of processing criteria and potential for human error. Such limitations have the potential to undermine the benefits of SRM-based approaches in quantitative proteomics and inhibit its widespread application, and have driven the design and implementation of automated processing software that can handle large datasets. Whilst the instrument vendors produce informatics solutions for their own platforms, these programs do not tend to be focused towards a specific application area, and therefore have generally been found to be unsuitable for processing large datasets generated in SRM-based quantitative proteomics experiments. Further, due to the proprietary nature of these software programs, the underlying algorithms are not necessarily in the public domain and thus are difficult to evaluate fully. Software packages tailored specifically for the purpose of SRM-based quantitative proteomics experiments have proven more successful, and these have tended to be open source and freely available. One of the first such packages available for this purpose was MRMer, which allows the visualization of SRM data encoded in the mzXML format, and integrates signals to facilitate quantification and calculates relative peak areas for product ions deriving from peptide isotopologs [162]. Similar functionality is available in Skyline, although this program is arguably more user-friendly due to its ability to accept data in both open source (mzXML and $\mathrm{mxML}$ ) and proprietary formats from all of the major tandem quadrupole manufacturers [163]. The limitation of both of these programs is the absence of any statistical treatment of the data within the software to account for the probability of defining nonspecific transitions and thus determine peptide false discovery rates (FDRs). This is particularly important as the risk of false positives is significant due to the complex nature of typical proteomic samples, even when a highly selective MS approach such as SRM is used. To address this, Reiter and coworkers recently reported the development of mProphet [128]. This program uses a set of decoy transitions as negative controls to allow an estimation of the frequency with which nontargeted analytes have similar precursor and product ion $\mathrm{m} / \mathrm{z}$ values to the peptides of interest and thus generate a detectable signal. Decoy transitions are derived from those generated for the peptides of interest by subtraction of a random integer between 3 and $10 \mathrm{~m} / z$ units from the precursor ion and addition of -5 and $5 \mathrm{~m} / \mathrm{z}$ units from the product ion, and are used to acquire data concurrently with the targeted peptides. Both sets of data are then used in a semi-supervised machine learning process, whereby scores for a number of features, such as peak shape and the relative intensities of the monitored product ions across the chromatographic peak, are used to ascertain whether two signals represent the light and heavy isotopologs for a given peptide. As the decoy transitions used in this processing are known negatives, they can be used by mProphet to confidently assign and thus quantify the targeted peptides and provide an associated FDR for the dataset. The ability to generate a FDR for a quantitative dataset is a significant advance in the field of quantitative proteomics as it allows an objective assessment of the data quality. It is anticipated that inclusion of a FDR will become a prerequisite for the publication of quantitative data based on SRM measurements in the future, in much the same way as it has become requisite for qualitative proteomics; mProphet thus provides a potential processing solution that will ensure the longevity of SRMbased quantification datasets [164].

\section{Examples of SRM in biological studies}

It would not be possible to provide a fully comprehensive review of all of the studies where quantitative proteomics has been performed using SRM given the uptake of the approach in recent years. Instead, a few of the most striking and influential examples of the power of the approach will be detailed. Broadly speaking, SRM has been applied in quantitative proteomics in the areas of systems biology and clinical proteomics. One of the first major systems biology studies to utilize SRM was reported by Wolf-Yadlin and coworkers, who used the approach to quantify temporal tyrosine phosphorylation profiles in EGF-stimulated human 
mammary epithelial cells using iTRAQ [165]. Using simplified samples that had undergone peptide immunoprecipitation using an antiphosphotyrosine antibody [166] and phosphopeptide enrichment by immobilized metal-affinity chromatography (IMAC), the authors quantified 199 phosphopeptides reproducibly at baseline and over six time points post-EGF stimulation in two biological replicates [167]. This represented a greater than threefold improvement in peptide quantifications over the DDA approach also applied in their study where time courses for only 63 phosphopeptides could be constructed due to the irreproducibility of detection inherent in this mode of operation. This study therefore displayed the benefits of a targeted MS strategy such as SRM to ensure that data is acquired for all peptides of interest in a proteomics experiment, allowing more comprehensive datasets to be compiled. Ordinarily, applying an iTRAQ quantification strategy would not be recommended as it mitigates the selectivity provided by SRM due to the fact that all of the precursor ions for a given sample are quantified using the same product ion. However, Wolf-Yadlin and coworkers were able to overcome this by using low complexity samples generated by their enrichment strategy, demonstrating conditions under which iTRAQ and SRM can be used in concert.

Another study that exquisitely emphasized the capability of SRM to produce comprehensive datasets, as well as to quantify proteins over a wide dynamic range, was reported by the group of Aebersold, one of the foremost exponents of SRM in proteomics. In this paper, the authors absolutely quantified 21 proteins spanning the entire dynamic range of approximately 4.5 orders of magnitude in S. cerevisiae; quantitative measurements between 39 and 996,503 copies per cell were recorded [65]. These values were obtained using a tryptic digest of an unfractionated whole-cell lysate, providing a perfect example of the power of SRM to selectively detect, and if required quantify, analytes over a wide dynamic range in complex matrices. The copies per cell values were in broad agreement with another study that quantified a large proportion of the $S$. cerevisiae proteome using quantitative western blotting, demonstrating that SRM-based quantitative proteomics can be used to validate measurements made by other techniques [64]. Moreover, the authors were also able to detect peptides from 37 proteins that had previously never been reported using either affinity-based technologies or shotgun proteomics, clearly emphasizing the added value that a targeted strategy using SRM can provide to a dataset by virtue of the low limits of detection that are possible, and thus the lack of bias towards higher abundant proteins. In the same study, the authors applied a SRM methodology to quantify 45 proteins involved in central carbon metabolism of $S$. cerevisiae over ten time points covering a series of different growth phases and the diauxic shift in three biological replicates, with a total analysis time of less than 2 days. The dataset was more comprehensive and covered a greater abundance range than any other proteomics studies previously reported for the pathway under investigation, and the dynamics of the network were shown to differ from those inferred from transcriptomics studies [168]. This observation highlighted the importance of proteomicsbased strategies for understanding biological processes and suggested that post-transcriptional regulation takes place under the conditions studied due to the disparity of the protein abundance measurements with those of their mRNA transcripts. This study therefore represented an extremely powerful demonstration of the ability of SRM to consistently and rapidly detect and produce accurate quantitative data for a collection of proteins for several biological replicates of cellular systems that had been differentially perturbed, which is critical for mathematically modeling biological systems.

Another SRM-based study from the same group focused on both central carbon and amino acid metabolism in S. cerevisiae under five metabolic states with the aim of determining whether enzymes that are not necessary for metabolic regulation become downregulated or nonexpressed under those conditions, and also whether the large number of isoenzymes that exist in these protein networks are functionally redundant [169]. Using a SILAC style experiment and quantifying relative to ${ }^{15} \mathrm{~N}$-labeled reference cells, the authors were able to detect 199 proteins of the 228 constituting the metabolic network under all five conditions. This allowed fold changes to be determined for each of the proteins, which were in accordance with expected behavior under the conditions of cell growth. The observation of the vast majority of the network under all five conditions was not expected, and was a virtue of reproducible detection afforded by SRM. The authors determined using flux-balance analysis that expression of only between 121 and 133 of the 228 proteins that make up the pathway would be necessary for each condition. Therefore, the detection of a far greater number of proteins was concluded to 
indicate that the cell maintains a basal level of non-necessary enzymes such that it can react rapidly to environmental changes. Such an inference with regards to the biology of $S$. cerevisiae could not have been made using a shotgun proteomics strategy, as the incompleteness of datasets generated using this approach would likely lead to false negatives. The study also demonstrated the sensitivity of SRM as the authors were able to quantify the changes in abundance when a protein changed its status from 'necessary' to 'non-necessary' based upon the flux-balance analysis. In some cases the fold changes were large, and for 36 proteins counterintuitive in that the abundance increased with a change from 'necessary' to 'non-necessary', but for about half of the instances a twofold or less change was measurable using SRM. The issue of isoenzyme redundancy was assessed quantitatively to determine whether regulation of these proteins was differential. The SRM dataset obtained was uniquely placed to test such a hypothesis due to its coverage of the vast majority of the isoenzymes in the network. Using hierarchical clustering analysis of the abundance changes, the authors determined that, generally, isoenzymes clustered into different branches. This indicated differential regulation under the conditions tested, thereby suggesting functional diversity and rationalizing their presence within the cell. Correlation of the protein-abundance patterns of the isoenzymes with those of proteins of known function allowed postulation of the different roles of the isoenzymes in the metabolic network.

SRM has also found application in the field of clinical proteomics, specifically in the quest for validated biomarkers of disease as it has the capacity to overcome many of the limitations of traditional immunoassays, such as ELISAs, both in terms of development time and financial costs, and the relative ease with which selective assays can be designed and implemented [170]. Pioneering work from the groups of Anderson [90] and Borchers [171] have demonstrated the suitability of SRM in a clinical setting in terms of analytical performance. These studies showed that absolute quantification of medium-to-high abundance proteins was possible using SRM assays with excellent linearity of response, precision and LLOQ in either whole [171] or depleted plasma where the six most abundant proteins were removed [90]. This is significant because large sample sets are required to validate a biomarker for clinical use so as to rule out the possibility of a false positive and to account for the wide biological variance in humans [172]. Therefore, a requirement to heavily prefractionate samples for biomarker validation is undesirable because of the significant cost in terms of instrument time required to acquire the necessary MS data. The capability of SRM to target analytes of interest in complex matrices therefore makes it readily applicable for detecting and quantifying peptides from relatively abundant potential biomarkers in plasma samples that have undergone no more than modest simplification, thus considerably increasing throughput. The use of strategies such as immunodepletion and immunoenrichment can enable access to the lowest decades of the plasma proteome's dynamic range, and in conjunction with SRM assays are likely to facilitate quantification of low-abundance proteins under consideration as biomarkers [173-178]. The use of a rapid methodology to simplify the matrix is likely to prove essential as it is anticipated that the most clinically useful biomarkers will be very dilute within plasma (ng ml-1 or lower) $[179,180]$.

A group led by Domon utilized an effective enrichment strategy to selectively isolate $N$-glycosites from plasma and quantified the presence of proteotypic tryptic peptides to as low as $10 \mathrm{amol}$ on-column (equivalent to $\sim 0.1$ ng $\mathrm{ml}^{-1}$ assuming $100 \%$ efficiency of the glycocapture methodology) [145,181]. The authors also tested their methodology by spiking a glycosylated recombinant protein, TMEM27, into plasma at a concentration of $10 \mathrm{ng} \mathrm{ml}^{-1}$ and quantifying it using an AQUA peptide, demonstrating 50\% recovery (i.e., a concentration of $5 \mathrm{ng} \mathrm{ml}^{-1}$ ). Quantification of the endogenous form of the protein was also reported at no greater than $2 \mathrm{ng} \mathrm{ml}^{-1}$ in the plasma samples analyzed. These results underline the usefulness of SRM and complementary enrichment or depletion strategies to quantify peptides in the concentration range required for biomarker validation. However, despite these enabling studies demonstrating the usability of SRM in clinical studies, to date no clinically deployable biomarkers have been discovered, verified and validated using proteomic technologies. This is largely due to the high costs associated with the rigorous and exhaustive experimentation required to illustrate that the proposed biomarkers from discovery studies change quantitatively upon development or progression of the disease and show that the protein is specific for the condition under consideration [182]. This process is required to 'credential' the candidate biomarker and support its progression to clinical validation. These 
high costs can potentially lead to no reward, as discovery studies often propose a large number of putative biomarkers for a given disease and determining which ones to commit resources to is fraught with risk.

Recently, two pipelines have been proposed to prioritize and verify putative biomarkers in a costeffective manner, both of which apply SRM as an integral part of the workflow [183,184]. Whiteaker and coworkers used a combination of semi-quantitative and quantitative SRM in their workflow, along with accurate inclusion mass screening (AIMS) [185], to triage potential biomarkers for breast cancer in mouse models, which facilitated a large-scale study and replicated the level of experimentation required to verify a biomarker in humans. The semi-quantitative SRM stage involved internal standardization of MS signal intensity using a set of 'housekeeping' proteins whose abundance remains approximately constant regardless of disease state (Bluemlein and Ralser have also recently suggested a similar methodology for label-free SRM quantification [186]). In this manner, relative changes in abundance of potential biomarkers during disease progression could be assessed. The combination of the two targeted MS strategies allowed the reduction of the number of candidate proteins that performed well in the earlier experiments (observed by AIMS using proteotypic peptides, good signal-to-background ratio for multiple transitions in the semi-quantitative SRM analyses) from 383 to 88 , which was deemed a manageable number for absolute quantification by SID-SRM-MS, with or without enrichment using stable-isotopes standards and capture by anti-peptide antibodies (SISCAPA) [173]. Whilst this was still a significant number of proteins to target, the generation of standards and quantitative assays for SRM is significantly quicker and cheaper than for immunoassays. These advantages, along with the capability of SRM to be highly multiplexed, allowed quantitative data for all of the putative biomarkers to be obtained in a timeframe estimated by the authors to be at least ninefold faster than if traditional approaches were applied. The quantitative data showed that 30 proteins from the SID-SRM-MS experiments and six proteins from the SISCAPA-SID-SRM-MS experiments were significantly upregulated in ten clinically apparent tumor-bearing mice compared with the ten controls. Whilst the upregulated proteins in this example had little clinical value as a mouse rather than a human model was used, the pipeline was shown to be readily capable of sifting a list of putative of biomarkers to identify the promising candidates and then verifying those candidates in rigorous quantitative experiments.

In a similar approach, Addona and coworkers used LC-MS/MS with DDA to generate a list of over 1100 unique proteins in blood taken from the coronary sinuses of patients at baseline and then 10 and $60 \mathrm{~min}$ after they had undergone planned myocardial infarction. They demonstrated that 121 of these proteins underwent a minimum fivefold change using label-free quantification in either of the post-planned myocardial infarction samples compared with baseline, and thus were potential biomarkers of cardiovascular injury. The authors then attempted to detect these putative biomarkers in peripheral blood using the targeted strategy of AIMS, reducing the list to 52 promising candidates, only three of which had antibody reagents available for the construction of ELISAs. Therefore, the ability to undertake absolute quantification using SIDSRM-MS was invaluable in this circumstance. The authors selected seven of the candidates for verification based upon information garnered from the literature and were able to quantify two or three peptides from each protein, with quantitative measurements as low as $1 \mathrm{ng} \mathrm{m}^{-1}$. The study also compared the performance of antibody-based detection for 12 of the initial 121 proteins prioritized during the DDA experiments for which suitable reagents were available (single antibody reagents for seven proteins, allowing western blot analysis, and ELISAs for one of these seven plus a further five proteins). Using these methods, the authors were unable to detect three of the endogenous proteins quantified by SID-SRM-MS, postulated to be due to interferences or partial enzymatic degradation by plasma proteases. These experiments, therefore, showed that MS-based detection can be equivalent to or even outperform traditional protein assays used in clinical settings. Pipelines such as those detailed above should help to realize the potential of MS-based proteomics to deliver clinically deployable biomarkers of disease in the future.

\section{Conclusion \& future perspective}

SRM has had a profound effect on the field of proteomics due to its ability to repeatably/ reproducibly detect and quantify target peptides in complex biological mixtures over several orders of magnitude without the need for extensive sample prefractionation. It has, therefore, allowed many of the limitations of shotgun proteomics experiments for quantification 
to be overcome, permitting many proteomics studies to garner greater amounts of information and thus increasing their value. The ability to perform highly multiplexed assays means that 'whole' biological pathways can be investigated in single experiments, leading to the rapid acquisition of comprehensive datasets containing accurate and precise quantitative data - a foundation for systems biology modeling. In the field of clinical proteomics, SRM technology has the potential to supplant ELISAs and other immunoassays for biomarker verification and validation by providing a 'fail fast, fail cheap' approach that can be used in the early stages of verifying potential candidates, as the time and cost of designing SRM assays is far less than that for the traditional methods that employ antibodies. The information garnered from SRM-based experiments could then facilitate the informed and cost-effective design of specific immunoassays, or be used to design SRM assays for clinical validation. Due to the obvious benefits of the experimental approach and the importance of the fields to which it is applied, it is anticipated that SRM-based proteomics will continue to be a growing and active area of research for many years to come, particularly as the limitations in the quantitative methodologies, for example, the detrimental effect of incomplete proteolysis, the relatively small number of peptides that can be targeted per injection of sample $(\sim<100)$, become appreciated to a greater extent and solutions to overcome them are developed.

Financial \& competing interests disclosure This work was financially supported by the UK Biotechnology and Biological Sciences Research Council (BBSRC) under grant BB/G009058/1. The authors have no other relevant affiliations or financial involvement with any organization or entity with a financial interest in or financial conflict with the subject matter or materials discussed in the manuscript apart from those disclosed.

No writing assistance was utilized in the production of this manuscript.

\section{Executive summary}

\section{Background}

- The field of proteomics has developed from a mainly qualitative science to one where quantification is now conducted using both relative and absolute approaches.

\section{Strategies for absolute quantification of proteins}

- Absolute quantification of proteins is achieved at the peptide level through the principle of surrogacy.

- Quantification can be achieved either by label-free or label-mediated strategies.

- Four principle label-mediated strategies have been reported: absolute quantification (AQUA), quantification concatamers (QconCAT), equimolarity through equalizer peptides (EtEP) and protein standards for absolute quantification (PSAQ). Each approach has advantages and disadvantages, and hence no one strategy is universally applicable.

\section{The application of selected reaction monitoring}

- Shotgun proteomic experiments lead to datasets that are incomplete and rarely reflect the true dynamic range of the samples analyzed.

- Selected reaction monitoring (SRM) on tandem quadrupole mass spectrometers can overcome the limitations of shotgun proteomics.

- SRM is frequently used in concert with absolute quantification approaches as both are targeted experimental strategies.

\section{Deployment of SRM in quantitative proteomics}

- Selection of peptides to allow accurate and precise quantification requires the consideration of many factors. The use of quantotypic peptides is advocated.

- SRM co-ordinates have four descriptors: a precursor ion $\mathrm{m} / \mathrm{z}$ value, a product ion $\mathrm{m} / \mathrm{z}$ value, a collision energy and a retention time.

- The selection of peptides and design of optimal SRM co-ordinates for their detection and/or quantification is typically achieved through a combination of theoretical and empirical approaches.

\section{Processing of SRM data from multiplexed experiments}

- Large-scale SRM proteomic experiments generate datasets that are beyond manual handling in a rigorous, objective and error-free manner.

- Open source software packages for handling SRM data from proteomic experiments enable automated processing.

" The program mProphet allows calculation of a false discovery rate, which facilitates statistical assessment of the quality of data generated in a SRM experiment.

\section{Examples of SRM in biological studies}

- SRM has found application in a range of biological studies, enabling quantitative measurements to facilitate mathematical modeling in systems biology and the validation of protein biomarkers in clinical proteomics. 


\section{References}

Papers of special note have been highlighted as:

- of interest

-" of considerable interest

- Wasinger VC, Cordwell SJ, Cerpa-Poljak A et al. Progress with gene-product mapping of the Mollicutes: Mycoplasma genitalium. Electrophoresis 16, 1090-1094 (1995).

- 2 Gygi SP, Rist B, Gerber SA, Turecek F, Gelb MH, Aebersold R. Quantitative analysis of complex protein mixtures using isotopecoded affinity tags. Nat. Biotechnol. 17, 994-999 (1999).

-3 Shiio Y, Aebersold R. Quantitative proteome analysis using isotope-coded affinity tags and mass spectrometry. Nat. Protoc. 1, 139-145 (2006).

- 4 Thompson A, Schäfer J, Kuhn K et al. Tandem mass tags: a novel quantification strategy for comparative analysis of complex protein mixtures by MS/MS. Anal. Chem. 75 , 1895-1904 (2003).

-5 Ross PL, Huang YN, Marchese JN et al. Multiplexed protein quantification in Saccharomyces cerevisiae using amine-reactive isobaric tagging reagents. Mol. Cell. Proteomics 3, 1154-1169 (2004).

-6 Raijmakers R, Berkers CR, de Jong A, Ovaa H, Heck AJR, Mohammed S. Automated online sequential isotope labeling for protein quantitation applied to proteasome tissue-specific diversity. Mol. Cell. Proteomics 7, 1755-1762 (2008).

7 Boersema PJ, Raijmakers R, Lemeer S, Mohammed S, Heck AJR. Multiplex peptide stable isotope dimethyl labeling for quantitative proteomics. Nat. Protoc. 4, 484-494 (2009).

- Ong S-E, Blagoy B, Kratchmarova I et al. Stable isotope labeling by amino acids in cell culture, SILAC, as a simple and accurate approach to expression proteomics. Mol. Cell. Proteomics 1, 376-386 (2002).

- 9 Ong S-E, Mann M. A practical recipe for stable isotope labeling by amino acids in cell culture (SILAC). Nat. Protoc. 1, 2650-2660 (2007).

10 Lanucara F, Eyers CE. Mass spectrometricbased quantitative proteomics using SILAC. Method. Enzymol. 500, 133-150 (2011).

-11 America AHP, Cordewener JHG. Comparative LC-MS. A landscape of peaks and valleys. Proteomics 8, 731-749 (2008).

12 Lundgren DH, Hwang S-I, Wu L, Han DK. Role of spectral counting in quantitative proteomics. Expert Rev. Proteomics 7, 39-53 (2010).

-13 Old WM, Meyer-Arendt K, Aveline-Wolf L et al. Comparison of label-free methods for quantifying human proteins by shotgun proteomics. Mol. Cell. Proteomics 4, 1487-1502 (2005).

14 Brönstrup M. Absolute quantification strategies in proteomics based on mass spectrometry. Expert Rev. Proteomics 1, 503-512 (2004).

-15 Brun V, Masselon C, Garin J, Dupuis A. Isotope dilution strategies for absolute quantitative proteomics. J. Proteomics 72, 740-749 (2009).

- Review of the key methodological approaches used in absolute quantification proteomics.

16 Dowling P, Meleady P, Henry M, Clynes M. Recent advances in clinical proteomics using mass spectrometry. Bioanalysis 2, 1609-1615 (2010).

17 Hester RL, Iliescu R, Summers R, Coleman TG. Systems biology and integrative physiology modelling. J. Physiol. 589, 1053-1060 (2011).

>18 Silva JC, GM V, Li G-Z, Vissers JPC, Geromanos SJ. Absolute quantification of proteins by LCMSE. Mol. Cell. Proteomics 5, 144-156 (2006).

- 19 Neilson KA, Ali NA, Muralidharan S et al. Less label, more free: approaches in label-free quantitative mass spectrometry. Proteomics 11 535-553 (2011).

20 Levin Y, Hradetzky E, Bahn S. Quantification of proteins using dataindependent analysis $\left(\mathrm{MS}^{\mathrm{E}}\right)$ in simple and complex samples: a systematic evaluation. Proteomics 11, 3272-3287 (2011).

21 Ludwig C, Claassen M, Schmidt A, Aebersold R. Estimation of absolute protein quantities of unlabeled samples by selected reaction monitoring mass spectrometry. Mol. Cell. Proteomics doi:10.1074/mcp. M1111.013987 (2012) (Epub ahead of print).

-22 Bantscheff M, Schirle M, Sweetman G, Rick J, Kuster B. Quantitative mass spectrometry in proteomics: a critical review. Anal. Bioanal. Chem. 389, 1017-1031 (2007).

-23 Ciccimaro E, Blair IA. Stable-isotope dilution LC-MS for quantitative biomarker analysis. Bioanalysis 2, 311-341 (2010).

$\checkmark 24$ Leito I, Herodes K, Huopolainen M et al. Towards the electrospray ionization mass spectrometry ionization efficiency scale of organic compounds. Rapid Commun. Mass Spectrom. 22, 379-384 (2008).

25 Oss M, Kruve A, Herodes K, Leito I. Electrospray ionization efficiency scale of organic compounds. Anal. Chem. 82, 2865-2872 (2010).

-26 King R, Bonfiglio R, Fernandez-Metzler C, Miller-Stein C, Olah T. Mechanistic investigation of ionization suppression in electrospray ionization. J. Am. Soc. Mass Spectrom. 11, 942-950 (2000).
-27 Trufelli H, Palma P, Famiglini G, Cappiello A. An overview of matrix effects in liquid chromatography-mass spectrometry. Mass Spectrom. Rev. 30, 491-509 (2011).

28 Desiderio DM, Kai M. Preparation of stable isotope-incorporated peptide internal standards for field desorption mass spectrometry quantification of peptides in biologic tissue. Biomed. Mass Spectrom. 10, 471-479 (1983).

29 Barr JR, Maggio VL, Patterson Jr DG et al. Isotope dilution mass spectrometric quantification of specific proteins: model application with apolipoprotein A-I. Clin. Chem. 42, 1676-1682 (1996).

-30 Gerber SA, Rush J, Stemman O, Kirschner MW, Gygi SP. Absolute quantification of proteins and phosphoproteins from cell lysates by tandem MS. Proc. Natl Acad. Sci. USA 100, 6940-6945 (2003).

\$1 Kirkpatrick DS, Gerber SA, Gygi SP. The absolute quantification strategy: a general procedure for the quantification of proteins and post-translational modifications. Methods 35, 265-273 (2005).

32 Kettenbach AN, Rush J, Gerber SA. Absolute quantification of protein and posttranslational modification abundance with stable isotope-labeled synthetic peptides. Nat. Protoc. 6, 175-186 (2011).

33 Papaioannou MD, Lagarrigues M, Vejnar CE et al. Loss of dicer in Sertoli cells has a major impact on the testicular proteome of mice. Mol. Cell. Proteomics doi:10.1074/mcp. M900587-MCP900200 (2011) (Epub ahead of print).

34 Phu L, Izrael-Tomasevic A, Matsumoto ML et al. Improved quantitative mass spectrometry methods for characterizing complex ubiquitin signals. Mol. Cell. Proteomics doi:10.1074/mcp.M1110.003756 (2011) (Epub ahead of print).

Brownridge P, Holman SW, Gaskell SJ et al. Global absolute quantification of a proteome: challenges in the deployment of a QconCAT strategy. Proteomics 11, 2957-2970 (2011).

36 Holzmann J, Pichler P, Madalinksi M, Kurzbauer R, Mechtler K. Stoichiometry determination of the MP1-p14 complex using a novel and cost-efficient method to produce an equimolar mixture of standard peptides. Anal. Chem. 81, 10254-10261 (2009).

-37 Beynon RJ, Doherty MK, Pratt JM, Gaskell SJ. Multiplexed absolute quantification in proteomics using artificial QCAT proteins of concatenated signature peptides. Nat. Methods 2, 587-589 (2005). 
-38 Johnson H, Eyers CE, Eyers PA, Beynon RJ, Gaskell SJ. Rigorous determination of the stoichiometry of protein phosphorylation using mass spectrometry. J. Am. Soc. Mass Spectrom. 20, 2211-2220 (2009).

39 Ding C, Li Y, Kim B-J et al. Quantitative analysis of cohesin complex stoichiometry and SMC3 modification-dependent protein interactions. J. Proteome Res. 10, 3652-3659 (2011).

40 Carroll KM, Simpson DM, Eyers CE et al. Absolute quantification of the glycolytic pathway in yeast: deployment of a complete QconCAT approach. Mol. Cell. Proteomics doi:10.1074/mcp.M1111.007633-007631 (2011) (Epub ahead of print).

41 Kito K, Ota K, Fujita T, Ito T. A synthetic protein approach toward accurate mass spectrometric quantification of component stoichiometry of multiprotein complexes. J. Proteome Res. 6, 792-800 (2007).

42 Brun V, Dupuis A, Adrait A et al. Isotopelabeled protein standards: toward absolute quantitative proteomics. Mol. Cell. Proteomics 6, 2139-2149 (2007).

43 Brownridge P, Beynon RJ. The importance of the digest: proteolysis and absolute quantification in proteomics. Methods 54 , 351-360 (2011).

- A detailed discussion of the significance of complete proteolysis in absolute quantification experiments, which is an often neglected but crucial consideration in the acquisition of accurate and precise measurements.

44 Coin I. The depsipeptide method for solid-phase synthesis of difficult peptides. J. Pept. Sci. 16, 223-230 (2010).

$\checkmark 4$ Pezeshki A, Vergote V, Van Dorpe S et al. Adsorption of peptides at the sample drying step: influence of solvent evaporation technique, vial material and solution additive. J. Pharmaceut. Biomed. 49, 607-612 (2009).

46 Mirzaei H, McBee JK, Watts J, Aebersold R. Comparative evaluation of current peptide production platforms used in absolute quantification in proteomics. Mol. Cell. Proteomics 7, 813-823 (2008).

47 Siepen JA, Keevil EJ, Knight D, Hubbard SJ. Prediction of missed cleavage sites in tryptic peptides aids protein identification in proteomics. J. Proteome Res. 6, 399-408 (2007).

48 Pritchard C, Quaglia M, Ashcroft AE, O'Connor G. Considering the advantages and pitfalls of the use of isotopically labeled protein standards for accurate protein quantification. Bioanalysis 3, 2797-2802 (2011).
49 Huillet C, Adrait A, Lebert D et al. Accurate quantification of cardiovascular biomarkers in serum using protein standard absolute quantification (PSAQ ${ }^{\mathrm{TM}}$ ) and selected reaction monitoring. Mol. Cell. Proteomics doi:10.1074/mcp.M1111.008235 (2012) (Epub ahead of print).

50 Gilmore JM, Washburn MP. Advances in shotgun proteomics and the analysis of membrane proteins. J. Proteomics 73, 2078-2091 (2010).

51 Skipp PJ, O'Connor D. Shotgun proteomics: Future perspective in bioanalysis. Bioanalysis 3, 2159-2160 (2011).

52 Griffiths WJ, Wang Y. Mass spectrometry: from proteomics to metabolomics and lipidomics. Chem. Soc. Rev. 38, 1882-1896 (2009).

53 Kebarle P, Verkerk UH. Electrospray: from ions in solution to ions in the gas phase, what we know now. Mass Spectrom. Rev. 28, 898-917 (2009).

54 Paizs B, Suhai S. Fragmentation pathways of protonated peptides. Mass Spectrom. Rev. 24, 508-548 (2005).

55 Mikesh LM, Ueberhide B, Chi A et al. The utility of ETD mass spectrometry in proteomic analysis. Biochim. Biophys. Acta 1764, 1811-1822 (2006).

56 Wiesner J, Premsler T, Sickmann A. Application of electron transfer dissociation (ETD) for the analysis of posttranslational modifications. Proteomics 8, 4466-4483 (2008).

-57 Wu S-L, Huehmer AFR, Hao Z, Karger BL. Online LC-MS approach combining collision-induced dissociation (CID), electron-transfer dissociation (ETD) and CID of an isolated charge-reduced species for the trace-level characterization of proteins with post-translational modifications. J. Proteome Res. 6, 4230-4244 (2007).

58 Jones AW, Cooper HJ. Dissociation techniques in mass spectrometry-based proteomics. Analyst 136, 3419-3429 (2011).

59 Thakur SS, Geiger T, Chatterjee B et al. Deep and highly sensitive proteome coverage by LC-MS/MS without pre-fractionation. Mol. Cell. Proteomics doi: $10.1074 / \mathrm{mcp}$. M1110.003699 (2011) (Epub ahead of print).

60 Simpson RJ, Connolly LM, Eddes JS, Pereira JJ, Moritz RL, Reid GE. Proteomic analysis of the human colon carcinoma cell line (LIM 1215): development of a membrane protein database. Electrophoresis 21, 1707-1732 (2000).

61 Keller BO, Sui J, Young AB, Whittal RM. Interferences and contaminants encountered in modern mass spectrometry. Anal. Chim. Acta 627, 71-81 (2008).

-62 Picotti P, Aebersold R, Domon B. The implications of proteolytic background for shotgun proteomics. Mol. Cell. Proteomics 6, 1589-1598 (2007).

63 de Godoy LM, Olsen JV, de Souza GA, Li G, Mortensen P, Mann M. Status of complete proteome analysis by mass spectrometry: SILAC labeled yeast as a model system. Genome Biol. 7, R50 (2006).

64 Ghaemmaghami S, Huh W-K, Bower K et al. Global analysis of protein expression in yeast. Nature 425, 737-741 (2003).

65 Picotti P, Bodenmiller B, Mueller LN, Domon B, Aebersold R. Full dynamic range proteome analysis of $S$. cerevisiae by targeted proteomics. Cell 138, 795-806 (2009).

- A large study enabled by the strengths of selected reaction monitoring (SRM), with absolute quantities of targeted yeast proteins determined in excess of four orders of magnitude. The application of the SRM approach to understanding a key biological pathway was also demonstrated.

66 Anderson NL, Anderson NG. The human plasma proteome: history, character, and diagnostic prospects. Mol. Cell. Proteomics 1 , 845-867 (2002).

67 Silva JC, Denny R, Dorschel CA et al. Quantitative proteomic analysis by accurate mass retention time pairs. Anal. Chem. 77, 2187-2200 (2005).

68 Tsou C-C, Tsai C-F, Tsui Y-H et al. IDEAL-Q, an automated tool for label-free quantitation analysis using an efficient peptide alignment approach and spectral data validation. Mol. Cell. Proteomics 9, 131-144 (2010).

-69 Wada K, Ogiwara A, Nagasaka K, Tanaka N, Komatsu Y. i-RUBY: a novel software for quantitative analysis of highly accurate shotgun-proteomics liquid chromatography/ tandem mass spectrometry data obtained without stable-isotope labeling of proteins. Rapid Commun. Mass Spectrom. 25, 960-968 (2011).

70 Bateman RH, Carruthers R, Hoyes JB et al. A novel precursor ion discovery method on a hybrid quadrupole orthogonal acceleration time-of-flight (Q-TOF) mass spectrometer for studying protein phosphorylation. J. Am. Soc. Mass Spectrom. 13, 792-803 (2002).

71 Chernushevich IV, Loboda AV, Thomson BA. An introduction to quadrupole-time-of-flight mass spectrometry. J. Mass Spectrom. 36, 849-865 (2001) 
72 Stafford GC, Kelley PE, Syka JEP, Reynolds WE, Todd JFJ. Recent improvements in and analytical applications of advanced ion trap technology. Int. J. Mass Spectrom. Ion Processes 60, 85-98 (1984).

73 Jonscher KR, Yates III JR. The quadrupole ion trap mass spectrometer - a small solution to a big challenge. Anal. Biochem. 244, 1-15 (1997).

74 Hager JW. A new linear ion trap mass spectrometer. Rapid Commun. Mass Spectrom. 16, 512-526 (2002).

75 Schwartz JC, Senko MW, Syka JEP. A two-dimensional quadrupole ion trap mass spectrometer. J. Am. Soc. Mass Spectrom. 13 659-669 (2002).

76 Douglas DJ, Frank AJ, Mao D. Linear ion traps in mass spectrometry. Mass Spectrom. Rev. 24, 1-29 (2005).

77 Loboda AV, Chernushevich IV. A novel ion trap that enables high duty cycle and wide $m / z$ range on an orthogonal injection TOF mass spectrometer. J. Am. Soc. Mass Spectrom. 20, 1342-1348 (2009).

78 Michalski A, Cox J, Mann M. More than 100,000 detectable peptide species elute in single shotgun proteomics runs but the majority is inaccessible to data-dependent LC-MS/MS. J. Proteome Res. 10, 1785-1793 (2011).

- Evidence for the limitations of data-dependent acquisition analysis in shotgun proteomics.

79 Murray KK, Boyd RK, Eberlin MN, Langley GJ, Li L, Naito Y. IUPAC standard definitions of terms relating to mass spectrometry: final recommendations. Proceedings of: the 56th ASMS Conference on Mass Spectrometry and Allied Topics. 1-5 June, Denver, CO, USA (2008).

80 Murray KK. Glossary of terms for separations coupled to mass spectrometry.

J. Chromatogr. A 1217, 3922-3928 (2010).

- 81 Kondrat RW, McClusky GA, Cooks RG. Multiple reaction monitoring in mass spectrometry/mass spectrometry for direct analysis of complex mixtures. Anal. Chem. 50, 2017-2021 (1978).

\2 Zakett D, Flynn GA, Cooks RG. Chlorine isotope effects in mass spectrometry by multiple reaction monitoring. J. Phys. Chem. 82, 2359-2362 (1978).

83 Yost RA, Enke CG. Triple quadrupole mass spectrometry for direct mixture analysis and structural elucidation. Anal. Chem. 51, 1251A-1264A (1979).

84 Douglas DJ. Linear quadrupoles in mass spectrometry. Mass Spectrom. Rev. 28, 937-960 (2009).
85 March RE. Quadrupole ion traps. Mass Spectrom. Rev. 28, 961-989 (2009).

-86 Lin S, Shaler TA, Becker CH. Quantification of intermediate-abundance proteins in serum by multiple reaction monitoring mass spectrometry in a single-quadrupole ion trap. Anal. Chem. 78, 5762-5767 (2006).

87 Shipkova P, Drexler DM, Langish R, Smalley J, Salyan ME, Sanders M. Application of ion trap technology to liquid chromatography/mass spectrometry quantitation of large peptides. Rapid Commun. Mass Spectrom. 22, 1359-1366 (2008).

-88 Tanaka N, Nagasaka K, Komatsu Y. Selected reaction monitoring by linear ion-trap mass spectrometry can effectively be applicable to simultaneous quantification of multiple peptides. Biol. Pharm. Bull. 34, 135-141 (2011).

89 Cohen AM, Mansour AAH, Banoub JH. Absolute quantification of Atlantic salmon and rainbow trout vitellogenin by the 'signature peptide' approach using electrospray ionization QqToF tandem mass spectrometry. J. Mass Spectrom. 41, 646-658 (2006).

\$0 Anderson L, Hunter CL. Quantitative mass spectrometric multiple reaction monitoring assays for major plasma proteins. Mol. Cell. Proteomics 5, 573-588 (2006).

91 Boyd RK, Basic C, Bethem RA. Trace Quantitative Analysis by Mass Spectrometry. John Wiley \& Sons, Ltd, Chichester, UK (2008).

-92 Addona TA, Abbatiello SE, Schilling B et al. Multi-site assessment of the precision and reproducibility of multiple reaction monitoring-based measurements of proteins in plasma. Nat. Biotechnol. 27, 633-641 (2009).

- A comprehensive multi-laboratory study that demonstrated the reproducibility of SRM in quantitative proteomics.

93 Kuster B, Schirle M, Mallick P, Aebersold R. Scoring proteomes with proteotypic peptide probes. Nat. Rev. Mol. Cell Bio. 6, 577-583 (2005).

94 Picotti P, Lam H, Campbell D et al. A database of mass spectrometric assays for the yeast proteome. Nat. Methods 5, 913-914 (2008).

95 Brot N, Weissbach H. Biochemistry and physiological role of methionine sulfoxide residues in proteins. Arch. Biochem. Biophys. 223, 271-281 (1983).

96 Froelich JM, Reid GE. The origin and control of ex vivo oxidative peptide modifications prior to mass spectrometry analysis. Proteomics 8, 1334-1345 (2008).
- 97 Khandke KM, Fairwell T, Chait BT, Manjula BN. Influence of ions on cyclization of the amino terminal glutamine residues of tryptic peptides of streptococcal PepM49 protein: resolution of cyclized peptides by HPLC and characterization by mass spectrometry. Int. J. Peptide Protein Res. 34, 118-123 (1989).

98 Han B, Higgs RE. Proteomics: from hypothesis to quantitative assay on a single platform. Guidelines for developing MRM assays using ion trap mass spectrometers. Brief. Funct. Genomic Proteomic 7, 340-354 (2008).

-99 Schechter I, Berger A. On the size of the active site in proteases. I. Papain. Biochem. Biophys. Res. Commun. 27, 157-162 (1967).

100 Craig R, Cortens JP, Beavis RC. Open source system for analyzing, validating, and storing protein identification data. J. Proteome Res. 3, 1234-1242 (2004).

101 Deutsch EW, Lam H, Aebersold R. PeptideAtlas: a resource for target selection for emerging targeted proteomics workflows. EMBO Rep. 9, 429-434 (2008).

- 102 Siepen JA, Belhajjame K, Selley JN et al. ISPIDER Central: an integrated database web-server for proteomics. Nucleic Acids Res. 36, W485-W490 (2008).

103 Vizcaíno JA, Côté R, Reisinger F et al. A guide to the Proteomics Identifications Database proteomics data repository. Proteomics 9, 4276-4383 (2009).

- 104 Mallick P, Schirle M, Chen SS et al. Computational prediction of proteotypic peptides for quantitative proteomics. Nat. Biotechnol. 25, 125-131 (2007).

105 Fusaro VA, Mani DR, Mesirov JP, Carr SA. Prediction of high-responding peptides for targeted protein assays by mass spectrometry. Nat. Biotechnol. 27, 190-198 (2009).

106 Eyers CE, Lawless C, Wedge DC, Lau KW, Gaskell SJ, Hubbard SJ. CONSeQuence: prediction of reference peptides for absolute quantitative proteomics using consensus machine learning approaches. Mol. Cell. Proteomics doi: 10.1074/mcp.M1110.003384 (2011) (Epub ahead of print).

107 Helsens K, Brusniak M-Y, Deutsch E, Moritz RL, Martens L. jTraML: An open source java API for TraML, the PSI standard for sharing SRM transitions. J. Proteome Res. 10, 5260-5263 (2011).

108 Deutsch EW, Chambers M, Neumann S et al. TraML - a standard format for exchange of selected reaction monitoring transition lists. Mol. Cell. Proteomics doi:10.1074/mcp.R1111.015040 (2011) (Epub ahead of print). 
109 Cham JA, Bianco L, Bessant C. Free computational resources for designing selected reaction monitoring transitions. Proteomics 10, 1106-1126 (2010).

110 Bertsch A, Jung S, Zerck A et al. Optimal de novo design of MRM experiments for rapid assay developing in targeted proteomics. J. Proteome Res. 9, 2696-2704 (2010).

$\checkmark 11$ Li S, Arnold RJ, Tang H, Radivojac P. On the accuracy and limits of peptide fragmentation spectrum prediction. Anal. Chem. 83, 790-796 (2011).

112 Willard BB, Kinter M. Effects of the position of internal histidine residues on the collision-induced fragmentation of triply protonated tryptic peptides. J. Am. Soc. Mass Spectrom. 21, 1262-1271 (2001).

-113 Schwartz BL, Bursey MM. Some proline substituent effects in the tandem mass spectrum of protonated pentaalanine. Biol. Mass Spectrom. 21, 92-96 (1992).

${ }_{114}$ Breci LA, Tabb DL, Yates III JR, Wysocki VH. Cleavage $N$-terminal to proline: analysis of a database of peptide tandem mass spectra. Anal. Chem. 75, 1963-1971 (2003).

-115 Huang Y, Triscari JM, Tseng GC et al. Statistical characterization of charge state and residue dependence of low-energy CID peptide dissociation patterns. Anal. Chem. 77, 5800-5813 (2005).

116 Picotti P, Rinner O, Stallmach R et al. High-throughput generation of selected reaction-monitoring assays for proteins and proteomes. Nat. Methods 7, 43-46 (2010).

- 117 Stergachis AB, MacLean B, Lee K, Stamatoyannopoulos JA, MacCoss MJ. Rapid empirical discovery of optimal peptides for targeted proteomics. Nat. Methods 1041-1043 (2011).

-118 Frewen BE, Merrihew GE, Wu CC, Noble WS, MacCoss MJ. Analysis of peptide MS/ MS spectra from large-scale proteomics experiments using spectrum libraries. Anal. Chem. 78, 5678-5684 (2006).

-119 Prakash A, Tomazela DM, Frewen B et al. Expediting the development of targeted SRM assays: using data from shotgun proteomics to automate method development. J. Proteome Res. 8, 2733-2739 (2009).

120 Lam H, Aebersold R. Building and searching tandem mass (MS/MS) spectral libraries for peptide identification in proteomics. Methods 54, 424-431 (2011).

- 121 Sleno L, Volmer DA. Ion activation methods for tandem mass spectrometry. J. Mass Spectrom. 39, 1091-1112 (2004).

- 122 Roepstorff P, Fohlman J. Proposal for a common nomenclature for sequence ions in mass spectra of peptides. Biol. Mass Spectrom. 11, 601-601 (1984).

123 Johnson RS, Martin SA, Biemann K. Collision-induced fragmentation of $(\mathrm{M}+\mathrm{H})^{+}$ ions of peptides. Side chain specific sequence ions. Int. J. Mass Spectrom. Ion Processes 86, 137-154 (1988).

124 Lau KW, Hart SR, Lynch JA, Wong SCC, Hubbard SJ, Gaskell SJ. Observations on the detection of $b$ - and $y$-type ions in the collisionally activated decomposition spectra of protonated peptides. Rapid Commun. Mass Spectrom. 23, 1508-1514 (2009).

125 Sherwood CA, Eastham A, Lee LW, Risler J, Vitek O, Martin DB. Correlation between $\mathrm{y}$-type ions observed in ion trap and triple quadrupole mass spectrometers. J. Proteome Res. 8, 4243-4251 (2009).

126 Sherman J, McKay MJ, Ashman K, Molloy MP. How specific is my SRM? The issue of precursor and product ion redundancy. Proteomics 9, 1120-1123 (2009).

127 Abbatiello SE, Mani DR, Keshishian H, Carr SA. Automated detection of inaccurate and imprecise transitions in peptide quantification by multiple reaction monitoring mass spectrometry. Clin. Chem. 56, 291-305 (2010).

128 Reiter L, Rinner O, Picotti P et al. mProphet: automated data processing and statistical validation for large-scale SRM experiments. Nat. Methods 8, 430-435 (2011).

-. Report of mProphet, a sophisticated software package for the automated processing of SRM data. First program to facilitate the calculation of a false discovery rate for a SRM dataset, allowing a hitherto unobtainable level of statistical evaluation.

$129 \mathrm{Hu}$ Q, Noll RJ, Li H, Makarov A, Hardman M, Cooks RG. The Orbitrap: a new mass spectrometer. J. Mass Spectrom. 40, 430-443 (2005).

130 Olsen JV, Macek B, Lange O, Makarov A, Horning S, Mann M. Higher-energy C-trap dissociation for peptide modification analysis. Nat. Methods 4, 709-712 (2007).

131 de Graaf EL, Altelaar AFM, van Breukelen B, Mohammed S, Heck AJR. Improving SRM assay development: a global comparison between triple quadrupole, ion trap and higher energy CID peptide fragmentation spectra. J. Proteome Res. 10, 4334-4341 (2011).

132 Olsen JV, Schwartz JC, Griep-Raming J et al. A dual pressure linear ion trap Orbitrap instrument with very high sequencing speed. Mol. Cell. Proteomics 8, 2759-2769 (2009).

133 Michalski A, Damoc E, Hauschild J-P et al. Mass spectrometry-based proteomics using $Q$ exactive, a high-performance benchtop quadrupole Orbitrap mass spectrometer. Mol. Cell. Proteomics doi: $10.1074 / \mathrm{mcp}$. M1111.011015 (2011) (Epub ahead of print).

134 Michalski A, Damoc E, Lange O et al. Ultra high resolution linear ion trap Orbitrap mass spectrometer (Orbitrap Elite) facilitates top down LC MS/MS and versatile peptide fragmentation modes. Mol. Cell. Proteomics doi:10.1074/mcp.O1111.013698 (2011) (Epub ahead of print).

135 Haller I, Mirza UA, Chait BT. Collision induced decomposition of peptides. Choice of collision parameters. J. Am. Soc. Mass Spectrom. 7, 677-681 (1996).

136 Jones JL, Dongré AR, Somogyi A, Wysocki VH. Sequence dependence of peptide fragmentation efficiency curves determined by electrospray ionization/surface-induced dissociation mass spectrometry. J. Am. Chem. Soc. 116, 8368-8369 (1994).

137 Dongré AR, Jones JL, Somogyi A, Wysocki VH. Influence of peptide composition, gas-phase basicity, and chemical modification on fragmentation efficiency: evidence for the mobile proton model. J. Am. Chem. Soc. 118, 8365-8374 (1996).

138 Mohammed S, Chalmers MJ, Gielbert J et al. A novel tandem quadrupole mass spectrometer allowing gaseous collisional activation and surface induced dissociation. J. Mass Spectrom. 36, 1260-1268 (2001).

1139 MacLean B, Tomazela DM, Abbatiello SE et al. Effect of collision energy optimization on the measurement of peptides by selected reaction monitoring (SRM) mass spectrometry. Anal. Chem. 82, 10116-10124 (2010).

140 Sherwood CA, Eastham A, Lee LW et al. Rapid optimization of MRM-MS instrument parameters by subtle alteration of precursor and product $m / z$ targets. J. Proteome Res. 8 , 3746-3751 (2009).

- 141 Holstein CA, Gafken PR, Martin DB. Collision energy optimization of $\mathrm{b}$ - and $\mathrm{y}$-ions for multiple reaction monitoring. J. Proteome Res. 10, 231-240 (2011).

142 Qin J, Chait BT. Preferential fragmentation of protonated gas-phase peptide ions adjacent to acidic amino acid residues. J. Am. Chem. Soc. 117, 5411-5412 (1995).

143 Qin J, Chait BT. Collision-induced dissociation of singly charge peptide ions in a matrix-assisted laser desorption ionization ion trap mass spectrometer. Int. J. Mass Spectrom. 190/191, 313-320 (1999).

$D_{144}$ Kapp EA, Schütz F, Reid GE et al. Mining a tandem mass spectrometry database to determine the trends and global factors influencing peptide fragmentation. Anal. Chem. 75, 6251-6264 (2003). 
145 Stahl-Zeng J, Lange V, Ossola R et al. High sensitivity detection of plasma proteins by multiple reaction monitoring of $\mathrm{N}$-glycosites. Mol. Cell. Proteomics 6, 1809-1817 (2007).

146 Fillâtre Y, Rondeau D, Jadas-Hécart A, Communal PY. Advantages of the scheduled selected reaction monitoring algorithm in liquid chromatography/electrospray ionization tandem mass spectrometry multi-residue analysis of 242 pesticides: a comparative approach with classical selected reaction monitoring mode. Rapid Commun. Mass Spectrom. 2010, 2453-2461 (2010).

147 Keshishian H, Addona T, Burgess M, Kuhn E, Carr SA. Quantitative, multiplexed assays for low abundance proteins in plasma by targeted mass spectrometry and stable isotope dilution. Mol. Cell. Proteomics 6, 2212-2229 (2007).

148 Keshishian H, Addona T, Burgess M et al. Quantification of cardiovascular biomarkers in patient plasma by targeted mass spectrometry and stable isotope dilution. Mol. Cell. Proteomics 8, 2339-2349 (2009).

149 Krokhin OV, Craig R, Spicer V et al. An improved model for prediction of retention times of tryptic peptides in ion pair reversed-phase HPLC. Its application to protein peptide mapping by off-line HPLC-MALDI MS. Mol. Cell. Proteomics 3, 908-919 (2004).

150 Petritis K, Kangas LJ, Yan B et al. Improved peptide elution time prediction for reversedphase liquid chromatography-MS by incorporating peptide sequence information. Anal. Chem. 78, 5026-5039 (2006).

151 Gorshkov AV, Tarasova IA, Evreinov VV et al. Liquid chromatography at critical conditions: comprehensive approach to sequencedependent retention time prediction. Anal. Chem. 78, 7770-7777 (2006).

- 152 Klammer AA, Yi X, MacCoss MJ, Noble WS Improving tandem mass spectrum identification using peptide retention time prediction across diverse chromatography conditions. Anal. Chem. 79, 6111-6118 (2007).

- 153 Baczek T, Kaliszan R. Predictions of peptides' retention times in reversed-phase liquid chromatography as a new supportive tool to improve protein identification in proteomics. Proteomics 9, 835-847 (2009).

154 Babushok VI, Zenkevich IG. Retention characteristics of peptides in RP-LC: peptide retention prediction. Chromatographia 72 , 781-797 (2010)

155 Moruz L, Tomazela D, Käll L. Training, selection and robust calibration of retention time models for targeted proteomics. J. Proteome Res. 9, 5209-5216 (2010).
156 Eyers CE, Simpson DM, Wong SCC, Beynon RJ, Gaskell SJ. QCAL - a novel standard for assessing instrument conditions for proteome analysis. J. Am. Soc. Mass Spectrom. 19, 1275-1280 (2008).

157 Taradfer A, Aumann L, Morbidelli M. The role of ion-pairing in peak deformations in overloaded reversed-phase chromatography of peptides. J. Chromatogr. A 1217, 7065-7073 (2010).

158 Tanaka N, Thornton ER. Isotopic effects in hydrophobic binding measured by highpressure liquid chromatography. J. Am. Chem. Soc. 98, 1617-1619 (1976).

159 Zhang R, Sioma CS, Wang S, Regnier FE. Fractionation of isotopically labeled peptides in quantitative proteomics. Anal. Chem. 73, 5142-5149 (2001).

160 Zhang R, Sioma CS, Thompson RA, Xiong L, Regnier FE. Controlling deuterium isotope effects in comparative proteomics. Anal. Chem. 74, 3662-3669 (2002).

161 Kiyonami R, Schoen A, Prakash A et al. Increased selectivity, analytical precision, and throughput in targeted proteomics. Mol. Cell. Proteomics doi:10.1074/mcp.M1110.002931 (2011) (Epub ahead of print).

162 Martin DB, Holzman T, May D et al. MRMer, an interactive open source and cross-platform system for data extraction and visualization of multiple reaction monitoring experiments. $\mathrm{Mol}$. Cell. Proteomics 7, 2270-2278 (2008).

163 MacLean B, Tomazela DM, Shulman N et al. Skyline: an open source document editor for creating and analyzing targeted proteomics experiments. Bioinformatics 26, 966-968 (2010).

- 164 Bradshaw RA, Burlingame AL, Carr S, Aebersold R. Reporting protein identification data: the next generation of guidelines. Mol. Cell. Proteomics 5, 787-788 (2006).

165 Wolf-Yadlin A, Hautaniemi S, Lauffenburger DA, White FM. Multiple reaction monitoring for robust quantitative proteomic analysis of cellular signaling networks. Proc. Natl Acad. Sci. USA 104, 5860-5865 (2007).

166 Ding S-J, Qian W-J, Smith RD. Quantitative proteomic approaches for studying phosphotyrosine signaling. Expert Rev. Proteomics 4, 13-23 (2007).

167 Dunn JD, Reid GE, Bruening ML. Techniques for phosphopeptide enrichment prior to analysis by mass spectrometry. Mass Spectrom. Rev. 29, 29-54 (2010).

168 Brauer MJ, Saldanha AJ, Dolinski K, Botstein D. Homeostatic adjustment and metabolic remodeling in glucose-limited yeast cultures. Mol. Biol. Cell 16, 2503-2517 (2005).

169 Costenoble R, Picotti P, Reiter L et al. Comprehensive quantitative analysis of central carbon and amino-acid metabolism in Saccharomyces cerevisiae under multiple conditions by targeted proteomics. Mol. Syst. Biol. doi:10.1038/msb.2010.1122 (2011) (Epub ahead of print).

170 Ewles M, Goodwin L. Bioanalytical approaches to analyzing peptides and proteins by LC-MS/MS. Bioanalysis 3, 1379-1397 (2011).

171 Kuzyk MA, Smith D, Yang J et al. Multiple reaction monitoring-based multiplexed, absolute quantitation of 45 proteins in human plasma. Mol. Cell. Proteomics 8, 1860-1877 (2009).

172 Rifai N, Gillette MA, Carr SA. Protein biomarker discovery and validation: the long and uncertain path to clinical utility. Nat. Biotechnol. 24, 971-983 (2006).

173 Anderson NL, Anderson NG, Haines LR, Hardie DB, Olafson RW, Pearson TW. Mass spectrometric quantitation of peptides and proteins using stable isotope standards and capture by anti-peptide antibodies (SISCAPA). J. Proteome Res. 3, 235-244 (2004).

174 Whiteaker JR, Zhang H, Eng JK et al. Head-to-head comparison of serum fractionation techniques. J. Proteome Res. 6, 828-836 (2007).

175 Bandow JE. Comparison of protein enrichment strategies for proteome analysis of plasma. Proteomics 10, 1416-1425 (2010).

176 Righetti PG, Fasoli E, Egisto B. Combinatorial peptide ligand libraries: the conquest of the 'hidden proteome' advances at great strides. Electrophoresis 32, 960-966 (2011).

177 Kuhn E, Whiteaker JR, Mani D et al. Inter-laboratory evaluation of automated, multiplexed peptide immunoaffinity enrichment coupled to multiple reaction monitoring mass spectrometry for quantifying proteins in plasma. Mol. Cell. Proteomics doi:10.1074/mcp.M1111.013854 (2011) (Epub ahead of print).

178 Becker JO, Hoofnagle AN. Replacing immunoassays with tryptic digestion-peptide immunoaffinity enrichment and LC-MS/ MS. Bioanalysis 4, 281-290 (2012).

179 Polanksi M, Anderson NL. A list of candidate cancer biomarkers for targeted proteomics. Biomark. Insights 1, 1-48 (2006).

180 Paulovich AG, Whiteaker JR, Hoofnagle AN, Wang P. The interface between biomarker discovery and clinical validation: the tar pit of the protein biomarker pipeline. Proteomics Clin. Appl. 2, 1386-1402 (2008). 
-181 Zhang H, Li X-j, Martin DB, Aebersold R. Identification and quantification of $N$-linked glycoproteins using hydrazide chemistry, stable isotope labeling and mass spectrometry. Nat. Biotechnol. 21, 660-666 (2003).

182 Makawita S, Diamandis EP. The bottleneck in the cancer biomarker pipeline and protein quantification through mass spectrometry-based approaches: current strategies for candidate verification. Clin. Chem. 56, 212-222 (2010).
183 Whiteaker JR, Lin C, Kennedy J et al. A targeted proteomics-based pipeline for verification of biomarkers in plasma. Nat. Biotechnol. 29, 625-634 (2011).

184 Addona TA, Shi X, Keshishian H et al. A pipeline that integrates the discovery and verification of plasma protein biomarkers reveals candidate markers for cardiovascular disease. Nat. Biotechnol. 29, 635-643 (2011).

185 Jaffe JD, Keshishian H, Chang B, Addona TA, Gillette MA, Carr SA. Accurate inclusion mass screening: a bridge from unbiased discovery to targeted assay development for biomarker verification. Mol. Cell. Proteomics 7, 1952-1962 (2008).

186 Bluemlein K, Ralser M. Monitoring protein expression in whole-cell extracts by targeted label- and standard-free LC-MS/MS. Nat. Protoc. 6, 859-869 (2011).

- Website

201 SRMAtlas. www.srmatlas.org 